\title{
Use of conventional flow resistance equations and a model for the Nikuradse roughness in vegetated flows at high submergence
}

\author{
Paola Gualtieri*, Sergio De Felice, Vittorio Pasquino, Guelfo Pulci Doria ${ }^{\dagger}$ \\ University of Naples Federico II, Department of Civil, Architectural and Environmental Engineering, Via Claudio 2180125 Napoli, Italy. \\ sdefelic@unina.it; vittorio.pasquino@unina.it \\ *Corresponding author. E-mail: paola.gualtieri@unina.it \\ $\dagger$ Deceased
}

\begin{abstract}
This study examines the problem of flow resistance due to rigid vegetation in open channel flow. The reliability of the conventional flow resistance equations (i.e. Keulegan, Manning and Chézy-Bazin) for vegetated flows at high submergence, i.e. $h / k>5$, (where $h=$ flow depth and $k=$ vegetation height) is assessed. Several modern flow resistance equations based on a two-layer approach are examined, showing that they transform into the conventional equations at high submergences. To compare the conventional flow resistance equations at high submergences, an experimental methodology is proposed and applied to the experimental data reported in the literature and collected for this study. The results demonstrate the reliability of the Keulegan equation in predicting the flow resistance. Based on the obtained results, a model to evaluate the Nikuradse equivalent sand-grain roughness, $k_{N}$, starting from the vegetation height and density, is proposed and tested.
\end{abstract}

Keywords: Open channel flows; Vegetated flows; Rigid vegetation; Flow resistance; Roughness coefficients; Nikuradse equivalent sand-grain roughness.

\section{INTRODUCTION}

In the past, vegetation on riverbeds was considered to be an unwanted source of flow resistance, and for this reason, it was commonly removed. Currently, the preservation of vegetation is relevant for the ecology of water systems (Arthington et al., 2010; Poff et al., 1997) and, in this context, it is important to understand and characterise vegetated flows.

The effects of vegetation on flow, primarily dependent on the vegetation characteristics, such as its height, stiffness and density, are known (Stott, 2010) to include the following:

- decrease in water velocity and an increase in water levels (i.e., a reduction of the flow discharge capacity);

- deposition of suspended sediments; an increase or decrease in local erosion;

- $\quad$ influence on flood propagation;

- interference with the use of the water for conveyance, navigation and swimming.

Recently, the effects of vegetation on the flow resistance, turbulence characteristics, sediment transport and aquatic interfaces in open channel flows were examined in experimental and numerical studies (Marion et al., 2014; Nepf, 2012; VargasLuna et al., 2015), also using physics-based methods, such as the Kolmogorov vortex cascade (Gioia and Bombardelli, 2002; Huthoff et al., 2007; Konings et al., 2012) and the genetic programming (Babovic, 2000; Babovic et al., 2001; Baptist et al., 2007).

This study examines the problem of characterising flow resistance due to fully submerged, rigid vegetation and focuses particularly on submergence, i.e., the ratio between the flow depth $h(\mathrm{~m})$ and the vegetation height $k(\mathrm{~m})$, (Nepf and Vivoni, 2000) higher than 5. This condition, which is typical in river systems with extreme discharge conditions and extensive floodplains (Augustijn et al., 2008; Harris et al., 2003), has been less frequently studied. Previous studies (Augustijn et al., 2008) found that the equations proposed and tested for medium submergences are not sufficiently accurate for high submerg- ences. Some authors (Augustijn, 2008; Huthoff, 2009, 2012; Huthoff et al., 2007; Lopez and Garcia, 1997, 2001) have also suggested that conventional flow resistance equations of Keulegan, Manning, Chézy-Bazin, could be used for high submergences.

Based on these considerations, the purposes of this study include the following: i) to assess the suitability of the conventional flow resistance equations for highly submerged, vegetated flows; ii) to choose the best equation among the three considered conventional equations; iii) to propose a model for the evaluation of the roughness height starting from the geometric characteristics of the vegetation and then show its good agreement with the experimental data.

\section{FLOW RESISTANCE IN OPEN CHANNEL FLOW}

For open channel flows, the Darcy-Weisbach, Manning and Chézy equations are the most commonly used flow resistance equations, which are described as follows, respectively:

$$
V=\sqrt{\frac{8 g}{f}} ; \quad V=\frac{K_{n}}{n} R^{2 / 3} S^{1 / 2} ; \quad V=C \sqrt{R S}
$$

where $V$ is the mean cross-sectional velocity $\left(\mathrm{ms}^{-1}\right), f$ is the Darcy-Weisbach friction factor, $n$ is the Manning roughness coefficient $\left(\mathrm{m}^{1 / 6}\right), C$ is the Chézy resistance factor $\left(\mathrm{m}^{1 / 2} \mathrm{~s}^{-1}\right), R$ is the hydraulic radius of the flow cross-section $(\mathrm{m}), g$ is the gravitational acceleration $\left(\mathrm{ms}^{-2}\right), S$ is the energy slope and $K_{n}\left(\mathrm{~m}^{1 / 2} \mathrm{~s}^{-1}\right)$ is a conversion factor (Yen, 1992, 2002). Comparing Equations (1) the following equivalencies are obtained:

$\sqrt{\frac{f}{8 g}}=\frac{n}{K_{n} R^{1 / 6}}=\frac{1}{C}$

Hereafter, a brief examination of each equation is presented, neglecting the viscosity and Reynolds number effects, due to the usually large Reynolds number in open channel flows. 
Keulegan equation, the friction factor $f$ and the Nikuradse equivalent sand-grain roughness $\boldsymbol{k}_{N}$

The following expression is known as the Keulegan equation:

$V=K_{\Phi} \log \left(K_{\rho} \frac{R}{k_{N}}\right) \sqrt{R S}$

where $K_{\rho}=12.2, K_{\Phi}=18.0 \mathrm{~m}^{1 / 2} \mathrm{~s}^{-1}$ (Chow, 1988), and $k_{N}(\mathrm{~m})$ is the Nikuradse equivalent sand-grain roughness. Merging the Darcy-Weisbach equation and the Colebrook-White equation (Colebrook, 1939), the following is obtained (Yen, 2002):

$V=-K_{1} \sqrt{8 g} \log \left(\frac{k_{N}}{K_{2} R}\right) \sqrt{R S}$

Consequently, Eqs. (3) and (4) are equivalent when $K_{\Phi}=K_{1}(8 \mathrm{~g})^{1 / 2}$ and $K_{\rho}=K_{2}$. According to Yen (2002), $K_{1}=2$ and, for wide, rectangular channels $K_{2}=12.32$, (Marchi, 1961a, 1961b).

\section{Manning equation, the roughness coefficient $n$ and the Strickler roughness height $\boldsymbol{k}_{S}$}

Strickler (1923) proposed the following relationship between the Manning roughness coefficient $n\left(\mathrm{~m}^{1 / 6}\right)$ and the Strickler roughness height $k_{S}(\mathrm{~m})$ (Chow, 1988):

$n=K_{n} \Phi_{S} k_{S}^{1 / 6}$

where $\Phi_{S}=0.0400 \mathrm{~m}^{-1 / 2} \mathrm{~s}$ (Huthoff et al., 2007). Merging the second equation in (1) and Eq. (5), it is possible to obtain:

$V=\frac{R^{2 / 3} S^{1 / 2}}{\Phi_{S} k_{S}^{1 / 6}}$

A theoretical derivation of the Manning equation was given by Gioia and Bombardelli (2002).

Chézy equation, the resistance factor $C$, the Bazin roughness coefficient $B$ and the Chézy-Bazin roughness height $k_{B}$

In Chézy equation the resistance factor $C$ can be evaluated via Bazin's formula (Bazin, 1865):

$C=\frac{B_{0}}{1+B / \sqrt{R}}$

where $B_{0}=87 \mathrm{~m}^{1 / 2} \mathrm{~s}^{-1}$ and $B$ is a roughness coefficient. For vegetated beds, it could be useful to define a Chézy-Bazin roughness size, $k_{B}(\mathrm{~m})$ via the following equation:

$B=\Phi_{B} k_{B}^{1 / 2}$

where $\Phi_{B}=4.00 \mathrm{~m}^{1 / 2} \mathrm{~s}$ makes $k_{B}$ of the same order as $k_{N}$ and $k_{S}$ for the same channel roughness. Merging the third equation in (1), Eqs. (7) and (8), it is possible to obtain:

$V=\frac{B_{0} R^{1 / 2} S^{1 / 2}}{1+\frac{\Phi_{B} k_{B}^{1 / 2}}{R^{1 / 2}}}$

\section{Comparisons of $k_{N}, k_{S}$ and $k_{B}$}

To compare $k_{N}, k_{S}$ and $k_{B}$, the following reasoning is developed.

After replacing $f$ with the first equation in (1) and Eq. (3), and $C, n$ and $B$ with Eqs. (7), (5) and (8), respectively, Eq. (2) becomes the following:

$\frac{1}{K_{\Phi} \log \left(K_{\rho} \frac{R}{k_{N}}\right)}=\frac{\Phi_{S} k_{S}{ }^{1 / 6}}{R^{1 / 6}}=\frac{1+\Phi_{B} k_{B}^{1 / 2} / R^{1 / 2}}{B_{0}}$

Eq. (10) can then be rendered non-dimensional, as shown by:

$\frac{1}{K_{\Phi} \log \left(K_{\rho} \frac{R}{k_{N}}\right)}=\frac{\Phi_{S}\left(k_{S} / k_{N}\right)^{1 / 6}}{\left(\frac{R}{k_{N}}\right)^{1 / 6}}=\frac{1+\Phi_{B} \frac{\left(k_{B} / k_{N}\right)^{1 / 2}}{\left(R / k_{N}\right)^{1 / 2}}}{B_{0}}$

which shows that $k_{S} / k_{N}$ and $k_{B} / k_{N}$ depend only on $R / k_{N}$ :

$\frac{k_{S}}{k_{N}}=\frac{R}{k_{N}}\left[\frac{1}{\Phi_{S} K_{\Phi} \log \left(K_{\rho} \frac{R}{k_{N}}\right)}\right]^{6}$

$\frac{k_{B}}{k_{N}}=\frac{R}{k_{N}}\left[\frac{B_{0}}{\Phi_{B} K_{\Phi} \log \left(K_{\rho} \frac{R}{k_{N}}\right)}-1\right]^{2}$

In Fig. 1, Eqs. (12) and (13) are represented.

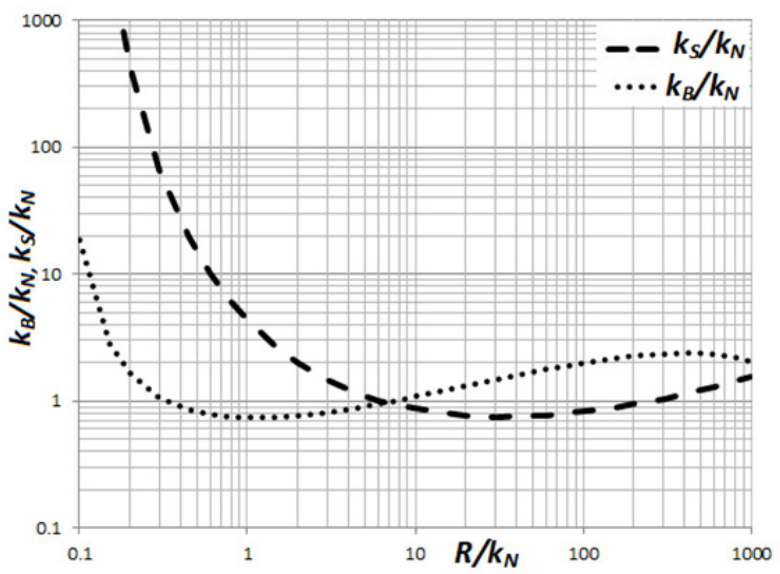

Fig. 1. Relationship among $k_{S} / k_{N}, k_{B} / k_{N}$ and $R / k_{N}$.

Moreover choosing $k_{B}$ or $k_{S}$ as the scales it is possible to obtain $k_{N} / k_{B}$ and $k_{S} / k_{B}$, and $k_{N} / k_{S}$ (Chow, 1988; Sturm, 2010) and $k_{B} / k_{S}$ as functions of $R / k_{N}$ (Figs. 2, 3).

Generally $k_{S}$ values are larger than the $k_{N}$ and $k_{B}$, which are more similar to each other due to the different assumption for the velocity distribution, namely, the power law for $k_{S}$ (Gioia and Bombardelli, 2002) and the logarithmic law for $k_{N}$ and $k_{B}$ (Baptist et al., 2007). The values of $k_{N}, k_{S}$ and $k_{B}$ are found to be different for $R / k_{N}$ in the range of $0.1-1$ but are only marginally different for $R / k_{N}$ in the range of $1-1000$. This observation is 


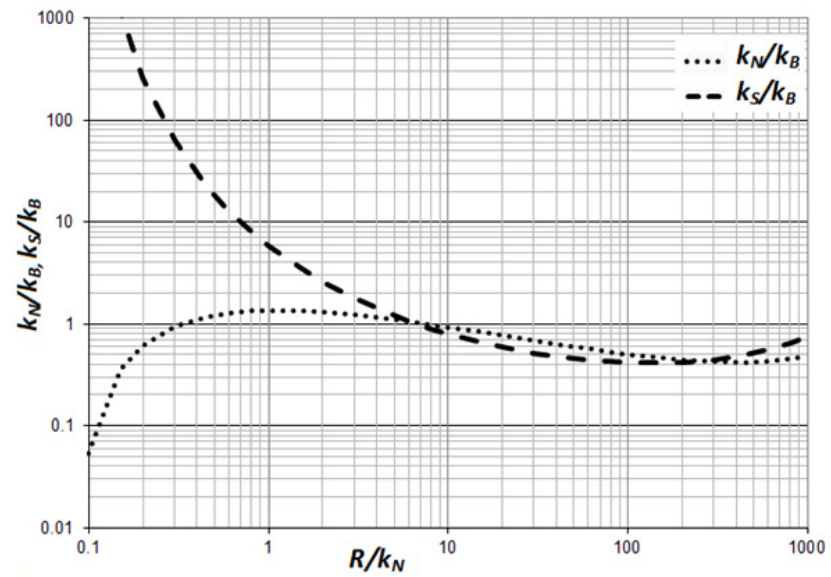

Fig. 2. Relationship among $k_{N} / k_{B}, k_{S} / k_{B}$ and $R / k_{N}$.

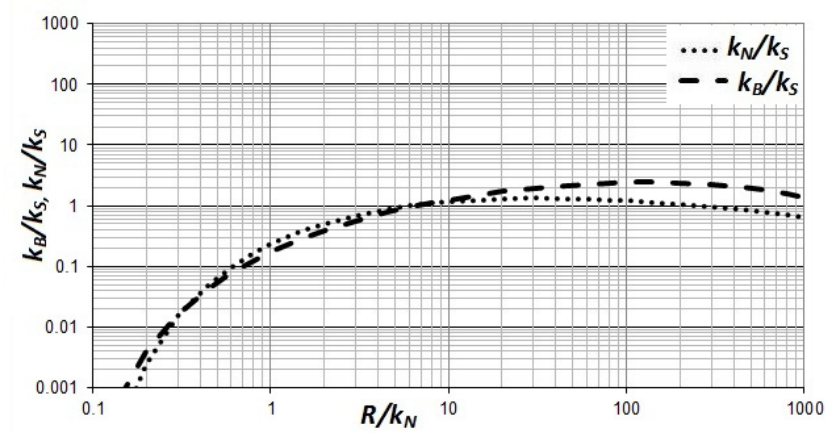

Fig. 3. Relationship among $k_{N} / k_{S}, k_{B} / k_{S}$ and $R / k_{N}$.

important for the purpose of this study: for rough riverbeds without vegetation, $R / k_{N}$ remains in the range of $1-1000$ (Chow, 1988), while for vegetated beds, as will be shown, $R / k_{N}$ remains in the range of $0.35-6.02$. Due to Eq. (4), the lowest physically acceptable value for $R / k_{N}$ is $1 / 12.32=0.0812$.

Hereafter, Eqs. (12) and (13) are used. The Keulegan, Manning and Chézy-Bazin equations state that $k_{N}, k_{S}$ and $k_{B}$ are relative to the wall roughness and are independent of the flow characteristics; consequently, while the left sides of Eqs. (12) and (13) are independent of the flow characteristics, the right sides are dependent on them due to $R$. Therefore, if in a certain range of flow conditions (i.e., $R$ values) one among the Keulegan, Manning and Chézy-Bazin equations yields a reliable evaluation of the flow resistance, the other two cannot, and thus, only one of the three equations may be considered valid within that range of flow conditions.

\section{FLOW RESISTANCE IN VEGETATED FLOWS}

One of the effects of vegetation is an increase in flow resistance, which is strongly influenced by the type of vegetation and the submergence. Vegetation may be modelled as either rigid, using wooden or metallic cylinders or stiff natural plants, or flexible, using plastic strips or flexible natural plants or grass. Vegetation may have different densities and can be wholly or partially submerged. Rigid vegetation allows for simple physics-based modelling and can be considered as a starting point to study the effects of flexible vegetation. In this study, vegetation modelled by rigid, equally spaced and completely submerged cylindrical elements is considered. Following the common assumptions of recent studies of vegetated flows, the two-dimensional approach (i.e., the hypothesis of a wide, rectangular channel) is assumed.

\section{Brief review of flow resistance in vegetated flows}

Conventional flow resistance equations are not valid for vegetated flows. One of the purposes of this study is to assess their use at high submergence. Firstly, a brief review of the flow resistance equations in vegetated flows is given. Most research is based on a two-layer approach (Fig. 4), which separately describes the velocity distribution in the vegetation layer and in the surface layer (Klopstra et al., 1997; Tsujimoto and Kitamura, 1990; Tsujimoto et al., 1992). The two distributions are matched at the separation surface, the mean cross-sectional velocity is obtained, and the flow resistance is evaluated.

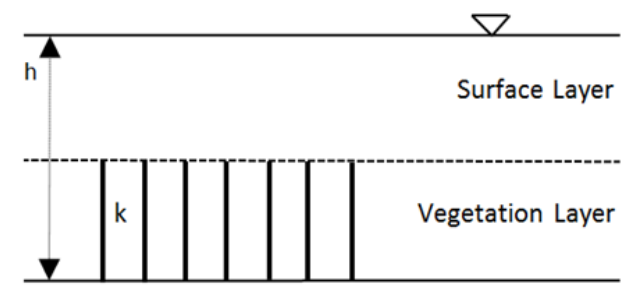

Fig. 4. Two-layer model.

For the vegetation layer, most authors consider the velocity to be constant, assuming a value obtained from the drag for a single element, as described in fluid mechanics. For the surface layer, some authors have assumed a logarithmic law, while others have used the Manning equation or another equation. This approach provides simple but sufficiently accurate flow resistance equations (Huthoff and Augustijn, 2006; Huthoff et al., 2007; Stone and Shen, 2002; Van Velzen et al., 2003). Starting from those equations, neglecting the bottom shear stresses (Nepf and Ghisalberti, 2008) and extracting the velocity, Galema (2009) obtained the following expressions:

a) Stone and Shen (2002), matching at the separation surface by assuming the ratio between the mean velocity in the channel and the velocity in the vegetation layer to be equal to $\sqrt{h / k}$, obtained the following expression:

$V=\sqrt{\frac{2 g}{C_{D} m D}} \sqrt{S}(1-D \sqrt{m}) \sqrt{\left(\frac{h}{k}-\frac{1}{4} \pi m D^{2}\right) \frac{h}{k}}$

where $h$ is the flow depth (m), $C_{D}$ is the drag coefficient of the cylindrical element, $D$ is the diameter $(\mathrm{m}), k$ is the height $(\mathrm{m})$ and $m$ is the number of elements per unit area $\left(\mathrm{m}^{-2}\right)$;

b) Van Velzen et al. (2003) assumed the logarithmic law in the surface layer and the resulting expression was:

$V=\sqrt{\frac{2 g}{C_{D} m D}} \sqrt{S}+K_{\Phi}(h-k)^{3 / 2} \frac{\sqrt{S}}{h} \log \frac{12(h-k)}{1.6 k^{0.7}}$

c) Huthoff and Augustijn (2006) and Huthoff et al. (2007) assumed in the surface layer the Manning equation, via Gioia and Bombardelli's (2002) approach, obtaining the following expression:

$V=\sqrt{\frac{2 g}{C_{D} m D}} \sqrt{S}\left[\sqrt{\frac{k}{h}}+\frac{h-k}{h}\left(\frac{h-k}{1 / \sqrt{m}-D}\right)^{2 / 3}\right]$

d) Keijzer and Babovic (2002), Babovic (2009) and Baptist et al. (2007) proposed a model based on genetic programming, obtaining the following expression: 
$V=\left(\sqrt{\frac{2 g}{C_{D} m D k}}+\frac{\sqrt{g}}{\kappa} \ln \left(\frac{h}{k}\right)\right) \sqrt{h S}$

where $\kappa$ is the von Kármán constant.

e) Yang and Choi (2010) obtained the following expression by assuming a logarithmic law for the surface layer:

$V=\left(\sqrt{\frac{2 g}{C_{D} m D k}}+C_{u} \frac{\sqrt{g}}{\kappa}\left[\ln \left(\frac{h}{k}\right)-\frac{h-k}{h}\right]\right) \sqrt{h S}$

where $C_{u}$ is a parameter whose value is equal to 1 or 2 depending on the value of $m D$, which is less or more than 5 , respectively;

f) Cheng (2011) defined the hydraulic radius as the ratio between the fluid-occupied volume and the total wetted surface area of the cylinders, obtaining the following expression:

$V=\left[\begin{array}{l}\sqrt{\frac{\pi\left(1-\lambda_{C}\right)^{3} D}{2 C_{D} \lambda_{C} k}\left(\frac{k}{h}\right)^{3 / 2}+} \\ +4.54\left(\frac{h-k}{D} \frac{1-\lambda_{C}}{\lambda_{C}}\right)^{1 / 16}\left(\frac{h-k}{h}\right)^{3 / 2}\end{array}\right] \sqrt{g h S}$

where $\lambda_{C}=\pi m D^{2} / 4$ is the fraction of the bed area occupied by the cylinders;

g) Konings et al. (2012), assumed Gioia and Bombardelli's (2002) approach and Huthoff et al. (2007), substituting $k_{S}$ for $n$ and making all terms non-dimensional, and obtained the following expression:

$$
\begin{aligned}
& \frac{(h-k)^{2}}{0.21 h^{2}}\left(\frac{h}{0.85 k}\right)^{1 / 3}\left(\frac{\sqrt{g} \Phi_{S} k_{S}^{1 / 6}}{h^{1 / 6}}\right)^{2}+ \\
& +\sqrt{\frac{2}{C_{D} m D k}} \frac{\sqrt{g} \Phi_{S} k_{S}^{1 / 6}}{h^{1 / 6}}-1=0
\end{aligned}
$$

In the work of Sturm (2010), the methods of Kouwen (1992) were investigated to represent the resistance due to non-bending (i.e., rigid) and bending vegetation; the MEI method was thus proposed based on $k_{N}$.

\section{Application of conventional flow resistance equations to vegetated flows at high submergence}

Some authors have examined the use of conventional flow resistance for vegetated flows, in specific flow conditions.

Nepf and Vivoni (2000) observed that a terrestrial canopy model, which is analogous to flow over a rough boundary, occurs in aquatic canopies deeply submerged, (i.e. $/ k>5$ ).

Lopez and Garcia (1997, 2001) showed that the Manning roughness coefficient, exhibits a nearly constant value up to some threshold of vegetation density. Conversely, a linear increase is observed after this limit is exceeded. Those authors thus evaluated the flow resistance with the Manning equation, assuming constant the flow depth (i.e., the hydraulic radius) and the vegetation height and neglecting the submergence. However, the authors referred to two limiting conditions: very high vegetation or very low vegetation.

Another approach was proposed in (Huthoff, 2009, 2012; Huthoff et al., 2007) considering the Kolmogorov theory of turbulence (Gioia and Bombardelli, 2002). Those authors eval- uated the flow resistance in the surface layer using the Manning equation, and obtained the following Strickler roughness height:

$$
k_{S} \approx \frac{\theta^{3}}{0.04^{6} g^{3} s^{2}}
$$

where $\theta(\mathrm{m})$ is the momentum thickness of the velocity distribution in the wakes of the cylinders and is evaluated by:

$\theta=\frac{1}{2} C_{D} D$

and $s$ is the average distance between the cylinders (m).

Augustijn et al. (2008), compared the equations of Keulegan, Manning, Chézy-Bazin, De Bos and Bijkerk (1963), Van Velzen et al. (2003), Baptist et al. (2007) and Huthoff et al. (2007). The results demonstrated that on average, the Keulegan equation showed the best agreement. The models proposed by Van Velzen et al. (2003), Baptist et al. (2007) and Huthoff et al. (2007) performed as well as those proposed by Keulegan (1938) and De Bos and Bijkerk (1963) without the disadvantage of an empirical parameter that must be calibrated. Increasing the submergence, the Manning coefficient decreases and eventually reaches a constant value, for $h / k>5$. However, when extrapolating at high submergence, the models showed a large uncertainty in evaluation of the flow resistance (Augustijn et al., 2008), showing that it is necessary to explore a wider range of flow conditions to identify the most suitable equation.

\section{Modern flow resistance equations for vegetated flows at high submergence}

In this section, Eqs. (14) - (20) are examined for high submergences (i.e., increasing $h / k$ to infinity).

As described in (Stone and Shen, 2002), for high submergences, in Eq. (14), the minor term in the brackets under the root can be neglected with respect to the other term that is greater than 1 and increases with the submergence. Consequently, Eq. (14) results:

$V=\sqrt{\frac{2 g}{C_{D} m D}}(1-D \sqrt{m}) \frac{\sqrt{h}}{k} \sqrt{h S}$

This expression can be considered to be the Chézy equation, where the resistance factor $C$ is:

$C=\sqrt{\frac{2 g}{C_{D} m D}}(1-D \sqrt{m}) \frac{\sqrt{h}}{k}$

Eq. (7), for high vegetation densities and therefore high values of $B$, results:

$C=\frac{B_{0} \sqrt{h}}{B}$

A comparison of Eqs. (24) and (25) results in the following:

$B=B_{0} \sqrt{\frac{C_{D} m D}{2 g}} \frac{k}{(1-D \sqrt{m})}$

and finally from Eq. (8): 
$k_{B}=\left(\frac{B_{0}}{\boldsymbol{\Phi}_{B}}\right)^{2}\left(\frac{C_{D} m D}{2 g}\right)\left[\frac{k}{(1-D \sqrt{m})}\right]^{2}$

Therefore, $k_{B}$ depends only on the vegetation characteristics, such as $C_{D}, D, k$ and $m$.

For high submergences, Eq. (15), neglecting the first term in the sum and the vegetation height with respect to the flow depth in the second term of the sum, results:

$$
V=K_{\Phi} \sqrt{h S} \log \frac{12 h}{1.6 k^{0.7}}
$$

Considering that $12 \approx 12.32$ (i.e., a wide rectangular channel), this expression is comparable to Keulegan equation, as shown below:

$k_{N}=1.6 k^{0.7}$

as suggested by the authors. Therefore, $k_{N}$ depends only on $k$. For high submergences Eq. (16), neglecting both the first term in the square brackets and the vegetation height with respect to the flow depth, results:

$V=\sqrt{\frac{2 g}{C_{D} m D}}\left(\frac{1}{1 / \sqrt{m}-D}\right)^{2 / 3} h^{2 / 3} \sqrt{S}$

This equation is comparable to the Manning equation, when $K_{n}$ is substituted, as shown below:

$n=K_{n} \sqrt{\frac{C_{D} m D}{2 g}}(1 / \sqrt{m}-D)^{2 / 3}$

and finally:

$k_{S}=\frac{1}{\Phi_{S}{ }^{6}}\left(\frac{C_{D} m D}{2 g}\right)^{3}\left(\frac{1-D \sqrt{m}}{\sqrt{m}}\right)^{4}$

Therefore, $k_{S}$ depends only on $C_{D}, D$, and $m$.

For high submergences, Eq. (17) neglecting the first term of the sum in parentheses, results:

$V=\left(\frac{\sqrt{g}}{\kappa} \ln \left(\frac{h}{k}\right)\right) \sqrt{h S}=\left(1.016 K_{\Phi} \log \left(\frac{K_{\rho} h}{12.32 k}\right)\right) \sqrt{h S}$

substituting $K_{\Phi}$ and $K_{\rho}$ for a wide, rectangular channel. This expression is also comparable to Keulegan equation, neglecting the factor 1.016 and considering:

$k_{N}=12.32 k$

as suggested by the authors. In this case, $k_{N}$ depends only on $k$.

For high submergences, Eq. (18) is the same as Eq.(17), after eliminating the term $(h-k) / k$ with respect to $\ln (h / k)$ if the product $m D$ is lower than 5 (i.e., $C_{u}=1$ ), which results in Eq. (33).

If the product $m D$ is higher than 5 (i.e., $C_{u}=2$ ), the following equation holds:
$V=\left(\frac{\sqrt{g}}{\kappa} 2 \ln \left(\frac{h}{k}\right)\right) \sqrt{h S}=\left(2.032 K_{\Phi} \log \left(\frac{K_{\rho} h}{12.32 k}\right)\right) \sqrt{h S}$

The resulting equation can no longer be compared to Keulegan equation, due to the impossibility of considering $K_{\Phi}$ equal to unity.

For high submergences, Eq. (19) becomes:

$V=\left[4.54\left(\frac{h}{D} \frac{1-\lambda_{C}}{\lambda_{C}}\right)^{1 / 16}\left(\frac{h-k}{h}\right)^{25 / 16}\right] \sqrt{g h S}$

Therefore, it tends to approach neither the Nikuradse nor the Manning equations.

In Eq. (20), for high submergence, where the second term is generally small and decreases, the first term strongly increases. Consequently, Eq. (20) becomes:

$\frac{1}{0.21}\left(\frac{1}{0.85}\right)^{1 / 3}\left(\frac{\sqrt{g} \Phi_{S} k_{S}^{1 / 6}}{k^{1 / 6}}\right)^{2}-1=0$

From this equation, $k_{S}$ can be calculated by:

$k_{S}=\frac{0.199}{g \Phi_{S}^{2}} k$

which depends only on $k$.

Therefore, for high submergences, nearly all of the previous equations can be approximated by one of the three classic flow resistance equations, and thus, $k_{N}, k_{S}$ or $k_{B}$ are functions of the vegetation characteristics as $k$ and/or $C_{D}, D$ or $m$. The different dependences of $k_{N}, k_{S}$ and $k_{B}$ on the geometric parameters of the vegetation suggests that, in agreement with Augustijn et al. (2008), the modern flow resistance equations are only approximately reliable when evaluating the flow resistance of vegetated flows at high submergences.

\section{Use of conventional flow resistance equations at high submergence}

As a consequence of the conclusions of the previous two paragraphs, it could be interesting to investigate the possibility of using one of the conventional flow resistance equations (i.e., the Keulegan, Manning and Chézy-Bazin equations) at high submergence, evaluating $k_{N}, k_{S}$ and $k_{B}$, and verify which of them, remaining constant for submergences higher than 5 , can therefore be considered to be a reliable expression of the flow resistance. To verify this point, a methodology described in a following paragraph can be applied to experimental data, found in the literature and collected for this study.

\section{EXPERIMENTAL MEASUREMENTS Experimental data found in the literature}

From the literature, a data set of twenty runs was selected. The experimental conditions of each run are summarised in Tables 1 and 2, where the following are reported: the flow rate $Q$, the velocity $V$, the uniform flow depth $h_{v}$, the Froude number $F r$, the geometric characteristics of the cylindrical elements (i.e., height $k$, diameter $D, m$ number of cylinders per unit area and the arrangement); the maximum submergence $(h / k)_{\max }$, 
Table 1. Experimental data from literature.

\begin{tabular}{|c|c|c|c|c|c|c|c|c|c|c|c|c|c|}
\hline Authors & Arr. & $Q\left(\mathrm{~m}^{-3} \mathrm{~s}^{-1}\right)$ & $V(\mathrm{~m} / \mathrm{s})$ & $h_{u}(\mathrm{~m})$ & $F r$ & $k(\mathrm{~m})$ & $D(\mathrm{~m})$ & $m\left(\mathrm{~m}^{-2}\right)$ & $\lambda$ & $h / k$ & $h / k_{N}(2)$ & $h / k_{N}(5)$ & Run \\
\hline \multirow{4}{*}{ Cheng (2011) } & \multirow{4}{*}{ St. } & 0.004 & 0.097 & 0.130 & 0.086 & 0.10 & 0.007 & 2221 & 1.466 & 1.300 & \multirow{4}{*}{0.17} & \multirow{4}{*}{$(0.35)$} & \multirow{4}{*}{ A1 } \\
\hline & & 0.006 & 0.131 & 0.150 & 0.108 & 0.10 & 0.007 & 2221 & 1.466 & 1.500 & & & \\
\hline & & 0.008 & 0.155 & 0.170 & 0.120 & 0.10 & 0.007 & 2221 & 1.466 & 1.700 & & & \\
\hline & & 0.010 & 0.158 & 0.200 & 0.113 & 0.10 & 0.007 & 2221 & 1.466 & 2.000 & & & \\
\hline \multirow{4}{*}{ Cheng (2011) } & \multirow{4}{*}{ St. } & 0.003 & 0.077 & 0.130 & 0.068 & 0.10 & 0.008 & 2221 & 1.800 & 1.300 & \multirow{4}{*}{0.19} & \multirow{4}{*}{$(0.39)$} & \multirow{4}{*}{$\mathrm{A} 2$} \\
\hline & & 0.005 & 0.102 & 0.150 & 0.084 & 0.10 & 0.008 & 2221 & 1.800 & 1.500 & & & \\
\hline & & 0.007 & 0.141 & 0.170 & 0.109 & 0.10 & 0.008 & 2221 & 1.800 & 1.700 & & & \\
\hline & & 0.011 & 0.190 & 0.200 & 0.136 & 0.10 & 0.008 & 2221 & 1.800 & 2.000 & & & \\
\hline \multirow{4}{*}{ Meijer and Van Velzen (1999) } & \multirow{4}{*}{ Al. } & 1.04 & 0.175 & 1.98 & 0.040 & 1.50 & 0.008 & 256 & 3.072 & 1.320 & \multirow{4}{*}{0.21} & \multirow{4}{*}{$(0.43)$} & \multirow{4}{*}{ A3 } \\
\hline & & 1.39 & 0.212 & 2.19 & 0.046 & 1.50 & 0.008 & 256 & 3.072 & 1.460 & & & \\
\hline & & 1.72 & 0.244 & 2.35 & 0.051 & 1.50 & 0.008 & 256 & 3.072 & 1.567 & & & \\
\hline & & 1.91 & 0.255 & 2.5 & 0.051 & 1.50 & 0.008 & 256 & 3.072 & 1.667 & & & \\
\hline \multirow{4}{*}{ Meijer and Van Velzen (1999) } & \multirow{4}{*}{ Al. } & 1.12 & 0.247 & 1.51 & 0.064 & 0.90 & 0.008 & 256 & 1.843 & 1.678 & \multirow{4}{*}{0.25} & \multirow{4}{*}{$(0.52)$} & \multirow{4}{*}{ A4 } \\
\hline & & 2.55 & 0.472 & 1.8 & 0.112 & 0.90 & 0.008 & 256 & 1.843 & 2.000 & & & \\
\hline & & 3.62 & 0.577 & 2.09 & 0.128 & 0.90 & 0.008 & 256 & 1.843 & 2.322 & & & \\
\hline & & 3.72 & 0.500 & 2.48 & 0.101 & 0.90 & 0.008 & 256 & 1.843 & 2.756 & & & \\
\hline \multirow{3}{*}{ Cheng (2011) } & \multirow{3}{*}{ St. } & 0.008 & 0.169 & 0.150 & 0.139 & 0.10 & 0.003 & 2221 & 0.711 & 1.500 & & & \\
\hline & & 0.011 & 0.216 & 0.170 & 0.167 & 0.10 & 0.003 & 2221 & 0.711 & 1.700 & 0.26 & $(0.54)$ & A5 \\
\hline & & 0.015 & 0.253 & 0.200 & 0.181 & 0.10 & 0003 & 2221 & 0.711 & 2.000 & & & \\
\hline & & 0.006 & 0.151 & 0.130 & 0.134 & 0.10 & 0.008 & 556 & 0.461 & 1.300 & & & \\
\hline & & 0.008 & 0.176 & 0.150 & 0.145 & 0.10 & 0.008 & 556 & 0.461 & 1.500 & & & \\
\hline Cheng (2011) & St. & 0.012 & 0.227 & 0.170 & 0.176 & 0.10 & 0.008 & 556 & 0.461 & 1.700 & 0.65 & $(0.55)$ & A6 \\
\hline & & 0.015 & 0.257 & 0.200 & 0.183 & 0.10 & 0.008 & 556 & 0.461 & 2.000 & & & \\
\hline & & 1.795 & 0.298 & 2.01 & 0.067 & 1.50 & 0.008 & 64 & 0.768 & 1.34 & & & \\
\hline & & 2.245 & 0.342 & 2.19 & 0.074 & 1.50 & 0.008 & 64 & 0.768 & 1.460 & & & \\
\hline Meijer and Van Velzen (1999) & Al. & 2.640 & 0.381 & 2.31 & 0.080 & 1.50 & 0.008 & 64 & 0.768 & 1.540 & 0.27 & $(0.56)$ & A7 \\
\hline & & 3042 & 0.409 & 2.48 & 0.083 & 1.50 & 0.008 & 64 & 0.768 & 1.653 & & & \\
\hline & & 0.006 & 0.159 & 0.130 & 0.141 & 0.10 & 0.007 & 556 & 0.367 & 1.300 & & & \\
\hline & & 0.010 & 0.213 & 0.150 & 0.176 & 0.10 & 0.007 & 556 & 0.367 & 1.500 & 028 & $(0-58)$ & $\Delta 8$ \\
\hline Cheng (2011) & St. & 0.012 & 0.241 & 0.170 & 0.187 & 0.10 & 0.007 & 556 & 0.367 & 1.700 & 0.28 & $(0.58)$ & A8 \\
\hline & & 0.016 & 0.268 & 0.200 & 0.192 & 0.10 & 0.007 & 556 & 0.367 & 2.000 & & & \\
\hline & & 0.014 & 0.286 & 0.120 & 0.263 & 0.06 & 0.006 & 2000 & 0.720 & 2.000 & & & \\
\hline Yan $(2008)$ & $\Delta 1$ & 0.023 & 0.307 & 0.180 & 0.231 & 0.06 & 0.006 & 2000 & 0.720 & 3.000 & & & \\
\hline Yan (2008) & Al. & 0.031 & 0.308 & 0.240 & 0.200 & 0.06 & 0.006 & 2000 & 0.720 & 4.000 & 0.40 & 0.63 & A9 \\
\hline & & 0.038 & 0.300 & 0.300 & 0.175 & 0.06 & 0.006 & 2000 & 0.720 & 5.000 & & & \\
\hline & & 1.75 & 0.384 & 1.51 & 0.100 & 0.90 & 0.008 & 64 & 0.461 & 1.678 & & & \\
\hline & & 3.53 & 0.498 & 1.78 & 0.158 & 0.90 & 0.008 & 64 & 0.461 & 1.978 & & & \\
\hline Meijer and Van Velzen (1999) & Al. & 4.72 & 0.613 & 2.06 & 0.170 & 0.90 & 0.008 & 64 & 0.461 & 2.289 & 0.37 & $(0.76)$ & A10 \\
\hline & & 4.77 & 0.760 & 2.47 & 0.131 & 0.90 & 0.008 & 64 & 0.461 & 2.74 & & & \\
\hline
\end{tabular}

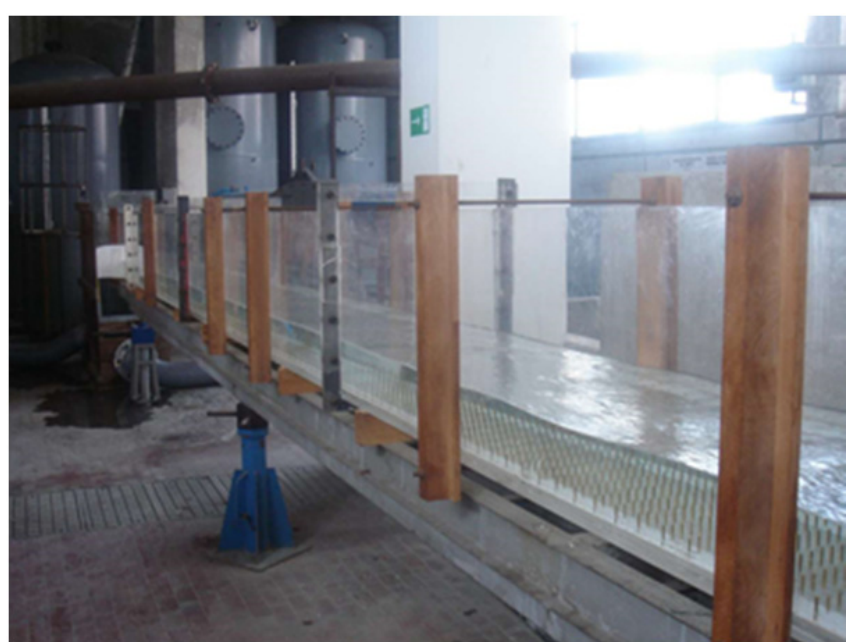

Fig. 5. Experimental flume.

which reaches or exceeds 5 in only five cases. The number of flow depths, which varies from 4 to 8 , except one case of 3 ; and the non-dimensional vegetation density $\lambda$, which ranges from 0.1306 to 3.072 and is evaluated as the product of $k, D$ and $m$. Due to the relevance of the parameter $h / k_{N}$, as shown in Eqs. (12) and (13), $h / k_{N}=2$ and $h / k_{N}=5$, which are denoted respectively

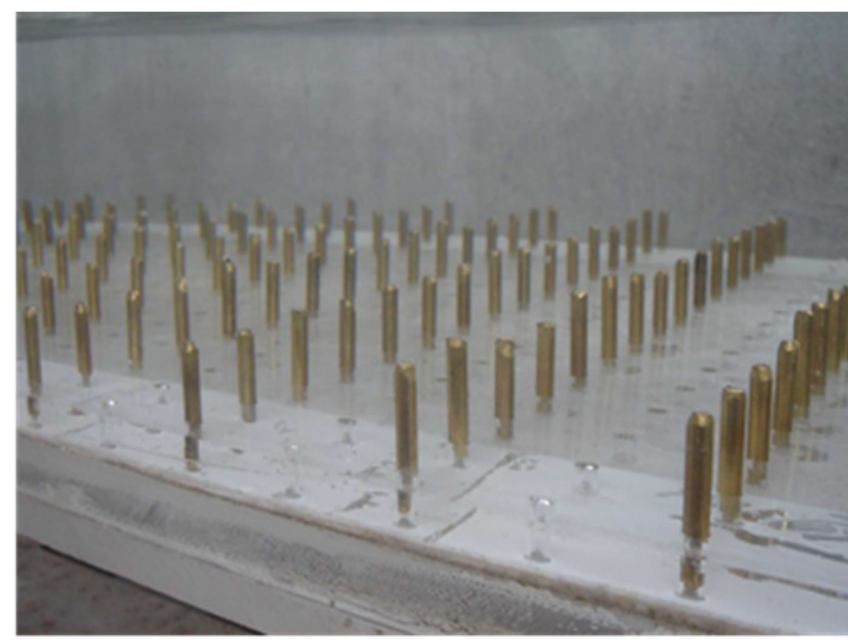

Fig. 6. Model of vegetation.

as $h / k_{N}(2)$ and $h / k_{N}(5)$, were evaluated and reported in Tables 1 and 2. In particular, each $h / k_{N}(5)$ value in brackets was obtained based on methodology that involves the experimental data collected for this study, which is described at the end of the following paragraph. The obtained $h / k_{N}(5)$ values range from 0.35 to 1.59 . 


\section{Experimental data collected for this study}

Experimental measurements were performed in a flume in the laboratory of the Department of Civil, Architectural and Environmental Engineering of the University of Naples Federico II, to extend the experimental conditions with respect to the data found in the literature. A channel with a variable slope was 8 -m long and had a cross-section of $0.40 \times 0.40 \mathrm{~m}^{2}$ (Fig. 5).

Vegetation covered the entire channel bed and consisted of rigid cylinders with heights of $\mathrm{k}=1.5 \mathrm{~cm}$ and diameters $D=$ $0.4 \mathrm{~cm}$ that were set in two arrangements (i.e., aligned and staggered) with three non-dimensional densities $\lambda$ (e.g., 0.024 , 0.048 and 0.096) (Fig. 6).

Ten runs were performed, each with 5 to 10 different flow depths. To extend the experimental conditions with respect to the data found in the literature, vegetation densities were lower, varying from 0.096 to 0.024 , and the submergences were higher, varying from 5 to 8.78 . Information relative to the experimental data set is summarised in Table 3.

In Table 3 , the values of $h / k_{N}(2)$ and $h / k_{N}(5)$ are reported, where the values of $h / k_{N}(5)$ are shown to vary from 1.60 to 6.02 , thus extending the range of the data found in the literature.

To obtain the values of $h / k_{N}(5)$ shown in brackets in Tables 1 and 2, the following methodology was applied: 15 runs (i.e., 5 from the literature and 10 from this study) were selected, where it was possible to evaluate $h / k_{N}(5)$ directly from the experimental data. A mean value of 2.06 of the ratios between $h / k_{N}(5)$ and $h / k_{N}(2)$ was calculated and was used to extrapolate the values of $h / k_{N}(5)$ in brackets in Tables 1 and 2, starting from the corresponding $h / k_{N}(2)$ values.

Table 2. Experimental data from literature.

\begin{tabular}{|c|c|c|c|c|c|c|c|c|c|c|c|c|c|}
\hline Authors & Arr. & $Q\left(\mathrm{~m}^{-3} \mathrm{~s}^{-1}\right)$ & $V(\mathrm{~m} / \mathrm{s})$ & $h_{u}(\mathrm{~m})$ & $F r$ & $k(\mathrm{~m})$ & $D(\mathrm{~m})$ & $m\left(\mathrm{~m}^{-2}\right)$ & $\lambda$ & $h / k$ & $h / k_{N}(2)$ & $h / k_{N}(5)$ & Run \\
\hline \multirow{8}{*}{ Tsujimoto et al. (1992) } & \multirow{8}{*}{ Al. } & 0.002 & 0.065 & 0.064 & 0.083 & 0.041 & 0.001 & 10000 & 0.410 & 1.551 & \multirow{8}{*}{0.39} & \multirow{8}{*}{$(0.80)$} & \multirow{8}{*}{ A11 } \\
\hline & & 0.005 & 0.140 & 0.066 & 0.174 & 0.041 & 0.001 & 10000 & 0.410 & 1.607 & & & \\
\hline & & 0.007 & 0.163 & 0.084 & 0.179 & 0.041 & 0.001 & 10000 & 0.410 & 2.054 & & & \\
\hline & & 0.009 & 0.201 & 0.085 & 0.220 & 0.041 & 0.001 & 10000 & 0.410 & 2.066 & & & \\
\hline & & 0.005 & 0.108 & 0.088 & 0.116 & 0.041 & 0.001 & 10000 & 0.410 & 2.154 & & & \\
\hline & & 0.009 & 0.182 & 0.094 & 0.189 & 0.041 & 0.001 & 10000 & 0.410 & 2.295 & & & \\
\hline & & 0.008 & 0.147 & 0.105 & 0.144 & 0.041 & 0.001 & 10000 & 0.410 & 2.571 & & & \\
\hline & & 0.011 & 0.199 & 0.106 & 0.195 & 0.041 & 0.001 & 10000 & 0.410 & 2.588 & & & \\
\hline \multirow{4}{*}{ Cheng (2011) } & \multirow{4}{*}{ St. } & 0.010 & 0.254 & 0.130 & 0.225 & 0.10 & 0.003 & 556 & 0.178 & 1.300 & \multirow{4}{*}{0.395} & \multirow{4}{*}{$(0.81)$} & \multirow{4}{*}{ A 12} \\
\hline & & 0.013 & 0.284 & 0.150 & 0.234 & 0.10 & 0.003 & 556 & 0.178 & 1.500 & & & \\
\hline & & 0.016 & 0.316 & 0.170 & 0.244 & 0.10 & 0.003 & 556 & 0.178 & 1.700 & & & \\
\hline & & 0.021 & 0.342 & 0.200 & 0.244 & 0.10 & 0.003 & 556 & 0.178 & 2.000 & & & \\
\hline \multirow{7}{*}{ Tsujimoto et al. (1992) } & \multirow{7}{*}{ Al. } & 0.003 & 0.124 & 0.057 & 0.165 & 0.046 & 0.002 & 2500 & 0.173 & 1.235 & \multirow{7}{*}{0.40} & \multirow{7}{*}{$(0.82)$} & \multirow{7}{*}{ A13 } \\
\hline & & 0.008 & 0.267 & 0.073 & 0.316 & 0.046 & 0.002 & 2500 & 0.173 & 1.580 & & & \\
\hline & & 0.005 & 0.179 & 0.074 & 0.211 & 0.046 & 0.002 & 2500 & 0.173 & 1.598 & & & \\
\hline & & 0.004 & 0.117 & 0.075 & 0.137 & 0.046 & 0.002 & 2500 & 0.173 & 1.628 & & & \\
\hline & & 0.012 & 0.331 & 0.090 & 0.353 & 0.046 & 0.002 & 2500 & 0.173 & 1.946 & & & \\
\hline & & 0.007 & 0.198 & 0.094 & 0.207 & 0.046 & 0.002 & 2500 & 0.173 & 2.035 & & & \\
\hline & & 0.005 & 0.133 & 0.095 & 0.137 & 0.046 & 0.002 & 2500 & 0.173 & 2.065 & & & \\
\hline \multirow{4}{*}{ Yan (2008) } & & 0.015 & 0.290 & 0.120 & 0.267 & 0.06 & 0.006 & 1000 & 0.360 & 2.000 & & & \\
\hline & & 0.023 & 0.300 & 0.180 & 0.226 & 0.06 & 0.006 & 1000 & 0.360 & 3.000 & & & \\
\hline & Al. & 0.030 & 0.300 & 0.240 & 0.195 & 0.06 & 0.006 & 1000 & 0.360 & 4.000 & 0.50 & 0.85 & A14 \\
\hline & & 0.037 & 0.292 & 0.300 & 0.170 & 0.06 & 0.006 & 1000 & 0.360 & 5.000 & & & \\
\hline & & 1.31 & 0.441 & 0.99 & 0.142 & 0.45 & 0.008 & 256 & 0.922 & 2.200 & & & \\
\hline & & 3.06 & 0.680 & 1.50 & 0.177 & 0.45 & 0.008 & 256 & 0.922 & 3.330 & & & \\
\hline Meijer and Van Velzen (1999) & Al. & 3.74 & 0.630 & 1.98 & 0.143 & 0.45 & 0.008 & 256 & 0.922 & 4.400 & 0.28 & 0.97 & A15 \\
\hline & & 5.92 & 0.836 & 2.46 & 0.174 & 0.45 & 0.008 & 256 & 0.922 & 5.467 & & & \\
\hline & & 0.179 & 0.587 & 0.35 & 0.324 & 0.1175 & 0.006 & 172 & 0.128 & 2.851 & & & \\
\hline & & 0.088 & 0.422 & 0.229 & 0.282 & 0.1175 & 0.006 & 172 & 0.128 & 1.949 & & & \\
\hline Dunn et al. (1996) & St. & 0.046 & 0.308 & 0.164 & 0.243 & 0.1175 & 0.006 & 172 & 0.128 & 1.396 & 0.55 & $(1.13)$ & A16 \\
\hline & & 0.178 & 0.709 & 0.276 & 0.431 & 0.1175 & 0.006 & 172 & 0.128 & 2.349 & & & \\
\hline & & 0.098 & 0.531 & 0.203 & 0.376 & 0.1175 & 0.006 & 172 & 0.128 & 1.728 & & & \\
\hline & & 0.046 & 0.308 & 0.164 & 0.243 & 0.12 & 0.006 & 170 & 0.131 & 1.367 & & & \\
\hline & & 0.098 & 0.531 & 0.203 & 0.376 & 0.12 & 0.006 & 170 & 0.131 & 1.692 & & & \\
\hline Lopez and Garcia (2001) & St. & 0.088 & 0.422 & 0.229 & 0.282 & 0.12 & 0.006 & 170 & 0.131 & 1.908 & 0.56 & $(1.15)$ & A17 \\
\hline & & 0.178 & 0.709 & 0.276 & 0.431 & 0.12 & 0.006 & 170 & 0.131 & 2.300 & & & \\
\hline & & 0.179 & 0.587 & 0.335 & 0.324 & 0.12 & 0.006 & 170 & 0.131 & 2.792 & & & \\
\hline & & 0.015 & 0.300 & 0.120 & 0.276 & 0.06 & 0.006 & 500 & 0.180 & 2.000 & & & \\
\hline Yan $(2008)$ & & 0.023 & 0.300 & 0.180 & 0.226 & 0.06 & 0.006 & 500 & 0.180 & 3.000 & & & \\
\hline Yan (2008) & Al. & 0.030 & 0.300 & 0.240 & 0.195 & 0.06 & 0.006 & 500 & 0.180 & 4.000 & 0.78 & 1.22 & Al8 \\
\hline & & 0.037 & 0.292 & 0.300 & 0.170 & 0.06 & 0.006 & 500 & 0.180 & 5.000 & & & \\
\hline & & 1.983 & 0.661 & 1.00 & 0.211 & 0.45 & 0.008 & 64 & 0.230 & 2.222 & & & \\
\hline & & 2.808 & 0.624 & 1.50 & 0.163 & 0.45 & 0.008 & 64 & 0.230 & 3.333 & & & \\
\hline Meijer and Van Velzen (1999) & Al. & 5.73 & 0.955 & 2.00 & 0.216 & 0.45 & 0.008 & 64 & 0.230 & 4.444 & 0.64 & 1.37 & A19 \\
\hline & & 6.57 & 0.883 & 2.48 & 0.179 & 0.45 & 0.008 & 64 & 0.230 & 5.511 & & & \\
\hline & & 0.0025 & 0.100 & 0.063 & 0.128 & 0.05 & 0.008 & 947 & 0.390 & 1.250 & & & \\
\hline & & 0.0030 & 0.100 & 0.075 & 0.117 & 0.05 & 0.008 & 947 & 0.390 & 1.500 & & & \\
\hline & $\Delta 1$ & 0.0040 & 0.100 & 0.100 & 0.101 & 0.05 & 0.008 & 947 & 0.390 & 2.000 & & & \\
\hline Nezu and Sanjou (2008) & Al. & 0.0050 & 0.100 & 0.125 & 0.090 & 0.05 & 0.008 & 947 & 0.390 & 2.500 & 0.77 & $(1.59)$ & A20 \\
\hline & & 0.0060 & 0.100 & 0.150 & 0.082 & 0.05 & 0.008 & 947 & 0.390 & 3.000 & & & \\
\hline & & 0.0080 & 0.100 & 0.200 & 0.071 & 0.05 & 0.008 & 947 & 0.390 & 4.000 & & & \\
\hline
\end{tabular}


Paola Gualtieri, Sergio De Felice, Vittorio Pasquino, Guelfo Pulci Doria

Table 3. Experimental data collected for this study.

\begin{tabular}{|c|c|c|c|c|c|c|c|c|c|c|c|c|c|}
\hline Authors & Arr. & $Q\left(\mathrm{~m}^{-3} \mathrm{~s}^{-1}\right)$ & $V(\mathrm{~m} / \mathrm{s})$ & $h_{u}(\mathrm{~m})$ & $F r$ & $k(\mathrm{~m})$ & $D(\mathrm{~m})$ & $m\left(\mathrm{~m}^{-2}\right)$ & $\lambda$ & $h / k$ & $h / k_{N}(2)$ & $h / k_{N}(5)$ & Run \\
\hline \multirow{10}{*}{ This Study } & \multirow{10}{*}{$\mathrm{Al}$. } & 0.003 & 0.268 & 0026 & 0.534 & 0.015 & 0.004 & 1600 & 0.096 & 1.720 & \multirow{10}{*}{0.69} & & \\
\hline & & 0.004 & 0.301 & 0.035 & 0.514 & 0.015 & 0.004 & 1600 & 0.096 & 2.333 & & & \\
\hline & & 0.005 & 0.343 & 0.039 & 0.553 & 0.015 & 0.004 & 1600 & 0.096 & 2.613 & & & \\
\hline & & 0.009 & 0.442 & 0.049 & 0.640 & 0.015 & 0.004 & 1600 & 0.096 & 3.233 & & & \\
\hline & & 0.014 & 0.555 & 0.064 & 0.702 & 0.015 & 0.004 & 1600 & 0.096 & 4.247 & & & \\
\hline & & 0.023 & 0.680 & 0.083 & 0.753 & 0.015 & 0.004 & 1600 & 0.096 & 5.540 & & 1.60 & B1 \\
\hline & & 0.027 & 0.751 & 0.091 & 0.795 & 0.015 & 0.004 & 1600 & 0.096 & 6.060 & & & \\
\hline & & 0.033 & 0.808 & 0.102 & 0.807 & 0.015 & 0.004 & 1600 & 0.096 & 6.807 & & & \\
\hline & & 0.045 & 0.924 & 0.122 & 0.846 & 0.015 & 0.004 & 1600 & 0.096 & 8.113 & & & \\
\hline & & 0.052 & 0.995 & 0.132 & 0.876 & 0.015 & 0.004 & 1600 & 0.096 & 8.780 & & & \\
\hline & & 0.004 & 0.416 & 0.023 & 0.876 & 0.015 & 0.004 & 1600 & 0.096 & 1.533 & & & \\
\hline & & 0.008 & 0.550 & 0.034 & 0.950 & 0.015 & 0.004 & 1600 & 0.096 & 2.280 & & & \\
\hline This Study & 1 & 0.013 & 0.707 & 0.045 & 1.065 & 0.015 & 0.004 & 1600 & 0.096 & 2.993 & & & \\
\hline This Study & A1. & 0.019 & 0.854 & 0.055 & 1.159 & 0.015 & 0.004 & 1600 & 0.096 & 3.687 & 0.72 & 1.77 & B2 \\
\hline & & 0.032 & 1.085 & 0.075 & 1.267 & 0.015 & 0.004 & 1600 & 0.096 & 4.980 & & & \\
\hline & & 0.052 & 1.342 & 0.098 & 1.372 & 0.015 & 0.004 & 1600 & 0.096 & 6.500 & & & \\
\hline & & 0.006 & 0.555 & 0.027 & 1.082 & 0.015 & 0.004 & 800 & 0.048 & 1.787 & & & \\
\hline & & 0.009 & 0.658 & 0.033 & 1.158 & 0.015 & 0.004 & 800 & 0.048 & 2.193 & & & \\
\hline & & 0.012 & 0.772 & 0.040 & 1.240 & 0.015 & 0.004 & 800 & 0.048 & 2.633 & & & \\
\hline & & 0.016 & 0.870 & 0.046 & 1.303 & 0.015 & 0.004 & 800 & 0.048 & 3.033 & & & \\
\hline & & 0.026 & 1.075 & 0.060 & 1.405 & 0.015 & 0.004 & 800 & 0.048 & 3.980 & & & \\
\hline This Study & St. & 0.039 & 1.274 & 0.077 & 1.470 & 0.015 & 0.004 & 800 & 0.048 & 5.100 & 1.13 & 1.26 & B3 \\
\hline & & 0.043 & 1.327 & 0.081 & 1.489 & 0.015 & 0.004 & 800 & 0.048 & 5.400 & & & \\
\hline & & 0.045 & 1.351 & 0.083 & 1.495 & 0.015 & 0.004 & 800 & 0.048 & 5.553 & & & \\
\hline & & 0.047 & 1.374 & 0.086 & 1.499 & 0.015 & 0.004 & 800 & 0.048 & 5.707 & & & \\
\hline & & 0.047 & 1.375 & 0.086 & 1.498 & 0.015 & 0.004 & 800 & 0.048 & 5.720 & & & \\
\hline & & 0.005 & 0.389 & 0.030 & 0.715 & 0.015 & 0.004 & 800 & 0.048 & 2.013 & & & \\
\hline & & 0.007 & 0.462 & 0.040 & 0.742 & 0.015 & 0.004 & 800 & 0.048 & 2.633 & & & \\
\hline & & 0.010 & 0.511 & 0.048 & 0.748 & 0.015 & 0.004 & 800 & 0.048 & 3.167 & & & \\
\hline This Study & Al. & 0.019 & 0.677 & 0.069 & 0.825 & 0.015 & 0.004 & 800 & 0.048 & 4.570 & 1.480 & 2.270 & B4 \\
\hline & & 0.030 & 0.824 & 0.090 & 0.879 & 0.015 & 0.004 & 800 & 0.048 & 5.973 & & & \\
\hline & & 0.043 & 0.961 & 0.111 & 0.921 & 0.015 & 0.004 & 800 & 0.048 & 7.397 & & & \\
\hline & & 0.052 & 1.046 & 0.124 & 0.949 & 0.015 & 0.004 & 800 & 0.048 & 8.267 & & & \\
\hline & & 0.006 & 0.510 & 0.030 & 0.943 & 0.015 & 0.004 & 800 & 0.048 & 1.987 & & & \\
\hline & & 0.008 & 0.572 & 0.035 & 0.979 & 0.015 & 0.004 & 800 & 0.048 & 2.320 & & & \\
\hline & & 0.010 & 0.640 & 0.041 & 1.015 & 0.015 & 0.004 & 800 & 0.048 & 2.700 & & & \\
\hline This Study & St. & 0.013 & 0.715 & 0.047 & 1.058 & 0.015 & 0.004 & 800 & 0.048 & 3.100 & 1.22 & 1.60 & B5 \\
\hline & & 0.021 & 0.878 & 0.060 & 1.142 & 0.015 & 0.004 & 800 & 0.048 & 4.013 & & & \\
\hline & & 0.023 & 0.915 & 0.064 & 1.156 & 0.015 & 0.004 & 800 & 0.048 & 4.260 & & & \\
\hline & & 0.034 & 1.083 & 0.080 & 1.226 & 0.015 & 0.004 & 800 & 0.048 & 5.307 & & & \\
\hline & & 0.005 & 0.397 & 0.033 & 0.698 & 0.015 & 0.004 & 800 & 0.048 & 2.193 & & & \\
\hline & & 0.008 & 0.467 & 0.040 & 0.743 & 0.015 & 0.004 & 800 & 0.048 & 2.687 & & & \\
\hline & & 0.011 & 0.551 & 0.050 & 0.788 & 0.015 & 0.004 & 800 & 0.048 & 3.327 & & & \\
\hline & & 0.017 & 0.674 & 0.064 & 0.852 & 0.015 & 0.004 & 800 & 0.048 & 4.253 & & & \\
\hline This Study & St. & 0.025 & 0.775 & 0.079 & 0.880 & 0.015 & 0.004 & 800 & 0.048 & 5.273 & 1.09 & 2.83 & B6 \\
\hline & & 0.025 & 0.783 & 0.079 & 0.887 & 0.015 & 0.004 & 800 & 0.048 & 5.293 & & & \\
\hline & & 0.028 & 0.823 & 0.085 & 0.900 & 0.015 & 0.004 & 800 & 0.048 & 5.687 & & & \\
\hline & & 0.029 & 0.830 & 0.086 & 0.903 & 0.015 & 0.004 & 800 & 0.048 & 5.747 & & & \\
\hline & & 0.039 & 0.947 & 0.103 & 0.942 & 0.015 & 0.004 & 800 & 0.048 & 6.880 & & & \\
\hline & & 0.009 & 0.747 & 0.029 & 1.400 & 0.015 & 0.004 & 400 & 0.024 & 1.933 & & & \\
\hline & & 0.011 & 0.835 & 0.033 & 1.474 & 0.015 & 0.004 & 400 & 0.024 & 2.183 & & & \\
\hline & & 0.016 & 0.966 & 0.041 & 1.527 & 0.015 & 0.004 & 400 & 0.024 & 2.717 & & & \\
\hline & & 0.023 & 1.105 & 0.051 & 1.559 & 0.015 & 0.004 & 400 & 0.024 & 3.417 & & & \\
\hline & & 0.030 & 1.245 & 0.060 & 1.618 & 0.015 & 0.004 & 400 & 0.024 & 4.020 & & & \\
\hline This Study & Al. & 0.033 & 1.296 & 0.064 & 1.641 & 0.015 & 0.004 & 400 & 0.024 & 4.240 & 2.47 & 4.24 & B7 \\
\hline & & 0.035 & 1.306 & 0.067 & 1.615 & 0.015 & 0.004 & 400 & 0.024 & 4.440 & & & \\
\hline & & 0.041 & 1.407 & 0.072 & 1.669 & 0.015 & 0.004 & 400 & 0.024 & 4.830 & & & \\
\hline & & 0.045 & 1.469 & 0.077 & 1.695 & 0.015 & 0.004 & 400 & 0.024 & 5.103 & & & \\
\hline & & 0.049 & 1.502 & 0.081 & 1.686 & 0.015 & 0.004 & 400 & 0.024 & 5.397 & & & \\
\hline & & 0.013 & 0.894 & 0.037 & 1.488 & 0.015 & 0.004 & 400 & 0.024 & 2.453 & & & \\
\hline & & 0.018 & 1.014 & 0.045 & 1.526 & 0.015 & 0.004 & 400 & 0.024 & 3.000 & & & \\
\hline This Study & St & 0.027 & 1.208 & 0.055 & 1.640 & 0.015 & 0.004 & 400 & 0.024 & 3.687 & 200 & 425 & PQ \\
\hline This Study & St. & 0.037 & 1.363 & 0.067 & 1.680 & 0.015 & 0.004 & 400 & 0.024 & 4.473 & 2.90 & 4.25 & B8 \\
\hline & & 0.033 & 1.307 & 0.063 & 1.661 & 0.015 & 0.004 & 400 & 0.024 & 4.207 & & & \\
\hline & & 0.052 & 1.552 & 0.085 & 1.705 & 0.015 & 0.004 & 400 & 0.024 & 5.633 & & & \\
\hline & & 0.007 & 0.502 & 0.033 & 0.883 & 0.015 & 0.004 & 400 & 0.024 & 2.193 & & & \\
\hline & & 0.010 & 0.596 & 0.041 & 0.939 & 0.015 & 0.004 & 400 & 0.024 & 2.733 & & & \\
\hline & & 0.014 & 0.704 & 0.051 & 0.992 & 0.015 & 0.004 & 400 & 0.024 & 3.420 & & & \\
\hline This Study & $\mathrm{Al}$. & 0.022 & 0.826 & 0.065 & 1.033 & 0.015 & 0.004 & 400 & 0.024 & 4.347 & 2.66 & 5.93 & B9 \\
\hline & & 0.033 & 0.978 & 0.084 & 1.076 & 0.015 & 0.004 & 400 & 0.024 & 5.620 & & & \\
\hline & & 0.033 & 0.964 & 0.084 & 1.059 & 0.015 & 0.004 & 400 & 0.024 & 5.627 & & & \\
\hline & & 0.045 & 1.103 & 0.102 & 1.103 & 0.015 & 0.004 & 400 & 0.024 & 6.793 & & & \\
\hline & & 0.007 & 0.502 & 0.033 & 0.883 & 0.015 & 0.004 & 400 & 0.024 & 2.193 & & & \\
\hline & & 0.010 & 0.594 & 0.041 & 0.936 & 0.015 & 0.004 & 400 & 0.024 & 2.740 & & & \\
\hline This Study & St. & 0.015 & 0.703 & 0.052 & 0.987 & 0.015 & 0.004 & 400 & 0.024 & 3.440 & 2.5 & 6.02 & $\mathrm{~B} 10$ \\
\hline & & 0.022 & 0.825 & 0.065 & 1.030 & 0.015 & 0.004 & 400 & 0.024 & 4.353 & & & \\
\hline & & 0.033 & 0.977 & 0.083 & 1.081 & 0.015 & 0.004 & 400 & 0.024 & 5.553 & & & \\
\hline
\end{tabular}



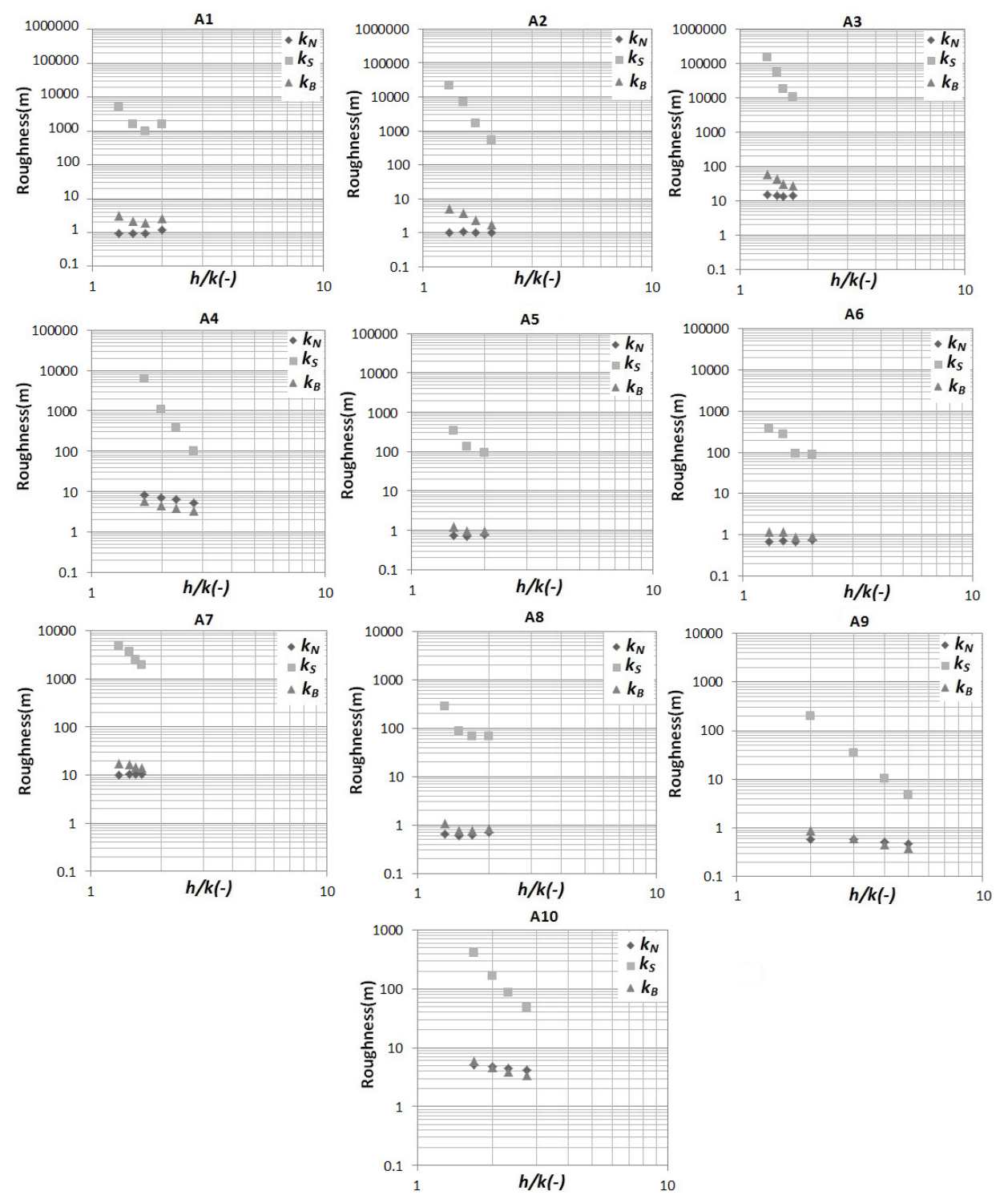

Fig. 7. Relationship among $k_{N}, k_{S}$ and $k_{B}$ with $h / k$ using the experimental data found in the literature.

RESULTS AND DISCUSSION

Methodology for verifying the use of conventional flow resistance equations at high submergence

From Eqs. (3), (6) and (9), $k_{N}, k_{S}$ and $k_{B}$ were evaluated for experimental data in Tables $1,2,3$. The results for each run are represented, respectively, in Figs. 7, 8, and 9. Each diagram is relative to a run: on the $\mathrm{x}$-axis, which is shown in a log scale for better visualisation, the flow depth is scaled with the height of the cylinders; and on the y-axis, which is shown in a log scale due to the many decades involved, the roughness is represented. The results show that Eqs. (3), (6) and (9) tested for vegetated flows at low and medium submergences are not sufficiently accurate showing, in some cases, values of $k_{S}, k_{B}$ and $k_{N}$ without physical meaning, and this is all the more true the greater the density is. The values of $k_{N}$ and $k_{B}$ are similar, while the values of $k_{S}$ are higher according to the comparison shown in Figs. 1, 2 and 3 .

\section{Comparison of the conventional flow resistance equations}

In each diagram in Figs. 7, 8 and 9, $k_{N}, k_{S}$ and $k_{B}$ differ; however, especially at higher submergences (i.e., $h / k \geq 5$ ), the val- ues show a general horizontal trend. The meaning of this trend is that the conventional flow resistance equations work better at higher submergence. It is thus necessary to determine which of the three roughnesses can be considered more reliable to evaluate the flow resistance in a vegetated flow.

To compare $k_{N}, k_{S}$ and $k_{B}$, the following methodology was applied. In each diagram, for each series of experimental data, the mean gradient was evaluated through a regression line; in Fig. 10, the three mean gradients are $+0.0012,-0.0124$ and +0.0016 . These mean gradients were then made nondimensional using the mean values of the ordinate (i.e., roughness) of the points of the series; in Fig. 10, these mean values are $0.0271,0.0688$ and 0.0215 , implying that the non-dimensional mean gradients are $+0.0443,-0.1802$ and +0.0746 .

For each series, the non-dimensional mean gradients were attributed to the mean value of the abscissae (i.e., submergences) of the points of the series; in Fig. 10, the mean value for each of the three series was 3.38 .

To compare the results of the diagrams, each nondimensional mean gradient was normalised with the value it would attain at the submergence $h / k=5$. These values were obtained by assuming that the non-dimensional mean gradient varies with the inverse of the submergence in each diagram; 

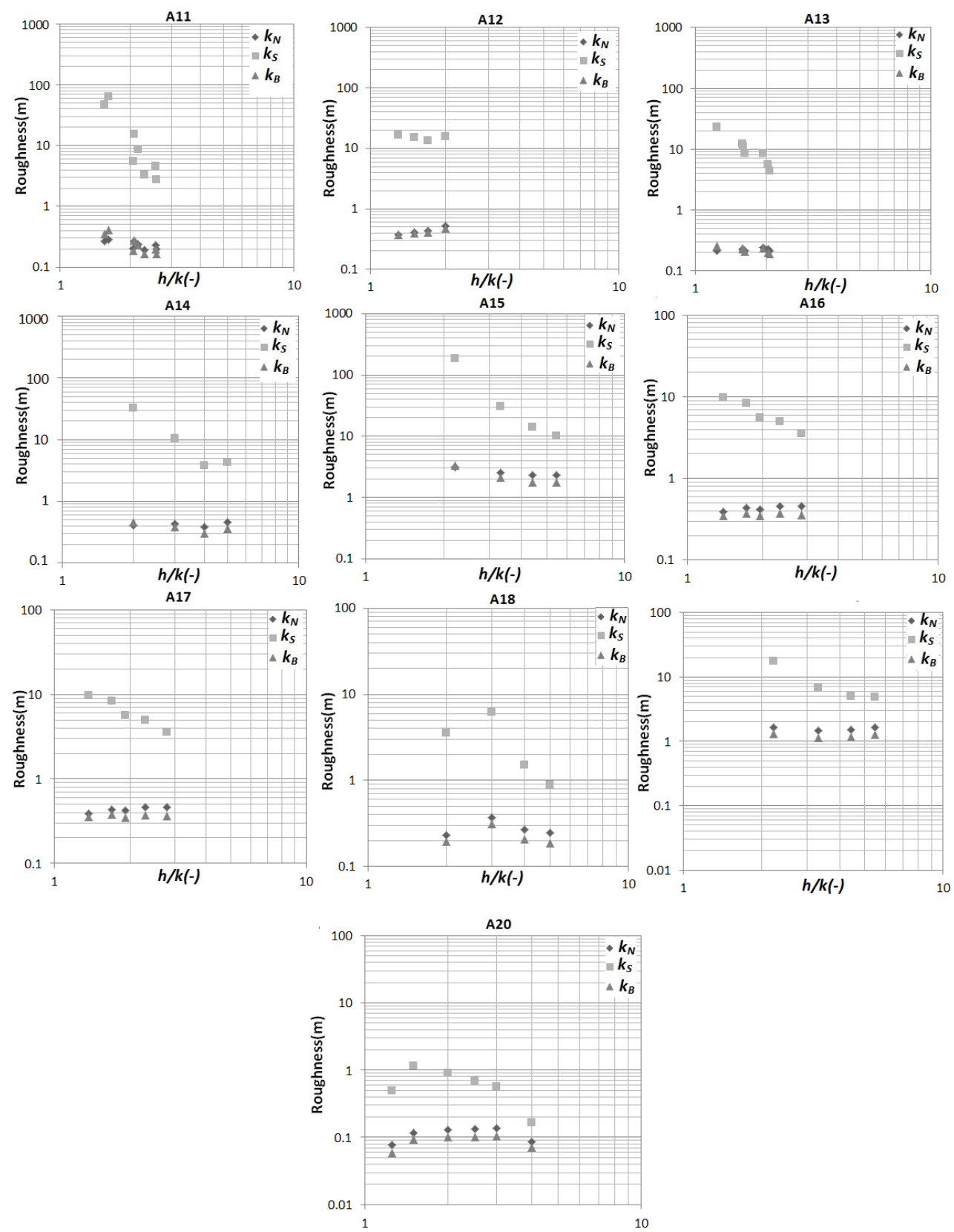

Fig. 8. Relationship among $k_{N}, k_{S}$ and $k_{B}$ with $h / k$ using the experimental data found in the literature.

this is the simplest assumption that leads to a horizontal trend with increasing values of submergence. Consequently, for each series, the normalising factor is the ratio between the mean submergence and 5; in Fig. 10, this ratio is $3.38 / 5=0.677$, which implies that the three non-dimensional normalised mean gradients are $+0.0300,-0.1202$ and 0.0505 .

In Fig. 11, the obtained non-dimensional normalised mean gradients, which are hereafter called gradients, of each run in Tables 1, 2 and 3 are reported versus the corresponding value of $h / k_{N}(5)$. It is evident that: 1$)$ as the value of $h / k_{N}(5)$ increases, the gradients relative to $k_{N}, k_{S}$ and $k_{B}$ tend to approach zero, indicating good reliability of the corresponding equations, increasing the submergence; and 2) the gradients relative to $k_{N}$ show the best trend.

The reliability of using the conventional flow resistance equations for vegetated flows with $h / k=5$ is demonstrated by the curves that approach 0 . To better show the trends of the data removing random variations, 5-point moving averages were calculated (Fig. 12).
A band \pm 0.05 was fixed so that a point inside it corresponded to a roughness varying by no more than $5 \%$ for a submergence varying by one unit.

Comparing the curves with the band, it is shown that the gradients relative to $k_{N}$ are always inside the band, irrespective of the value of $h / k_{N}(5)$, while the gradients relative to $k_{B}$ are within the band only when $h / k_{N}(5)>1$, and the gradients relative to $k_{S}$ are within the band only when $h / k_{N}(5)>3$. Consequently, remembering that $h / k_{N}(5)$ varies from 0.35 to 6.02 , the previous results show that for $h / k \geq 5$, it is better to use the Keulegan equation rather than the Manning or Chézy-Bazin equations.

\section{Model for the evaluation of the Nikuradse equivalent sand-grain roughness $\boldsymbol{k}_{N}$}

Starting from the conclusion of the previous paragraph, it is possible to select two groups of experimental runs from the literature and collected for this study, when $h / k \geq 5$. The first 

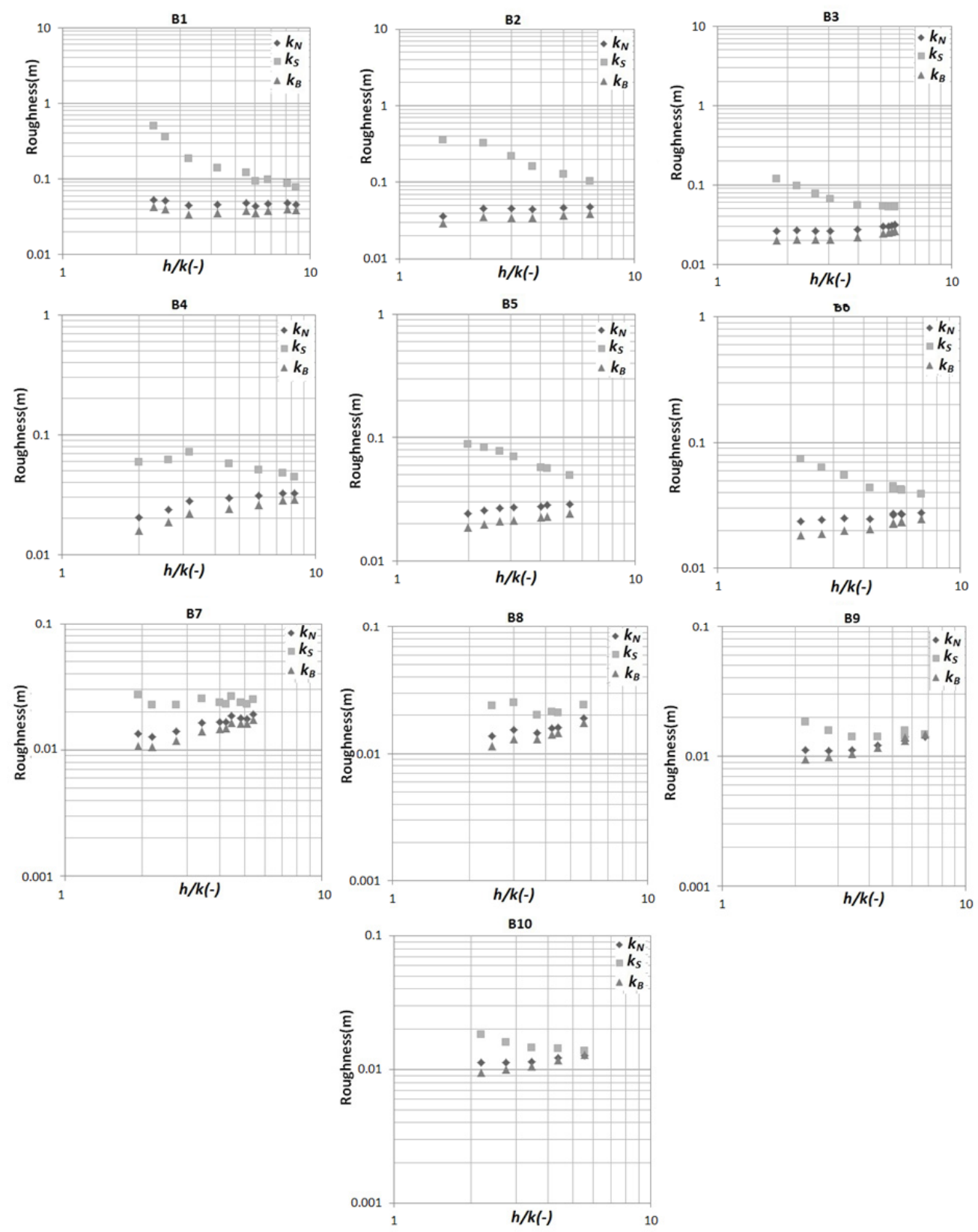

Fig. 9. Relationship of $k_{N}, k_{S}$ and $k_{B}$ with $h / k$ for this study's experimental conditions.

group are 3 runs out of a total of 75 runs from the literature and the second group are 27 runs out of a total 90 runs collected for this study. In Fig. 13, the first group of 3 runs is represented by squares, and the second group of 27 runs is represented by rhombuses. In Fig. 13, the density is shown on the $\mathrm{x}$-axis in a logarithmic scale, and the corresponding value of $k_{N} / k$ when $h / k>5$ is shown on the $y$-axis for each run.

Interpolating the points with a logarithmic curve, the graph shows a strong correlation $\left(R^{2}=0.93\right)$ between these two quantities; thus, it is possible to state that:

$$
\frac{k_{N}}{k}=2.0116 \ln \lambda+8.1916 \text { or } k_{N}=k[2.0116 \ln \lambda+8.1916]
$$

Runs from the literature have densities greater than 0.1 , while the runs collected for this study have densities lower than 0.1 . The first group shows a spread larger than the second group, with respect to the regression line. This diversity does not depend on the parameter $D / k$, as suggested by the dimensional

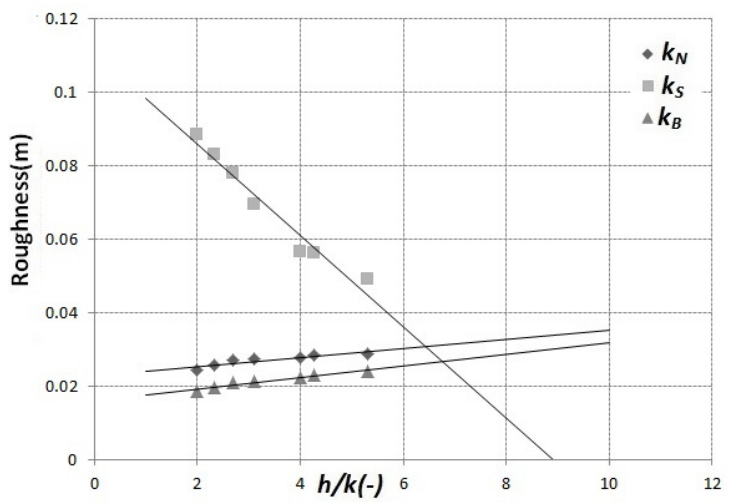

Fig. 10. Example of the regression lines for the experimental data.

considerations. Although the first group exhibits values of this parameter that are lower than the constant value of the second group, the members of the first group lie on both sides of the 


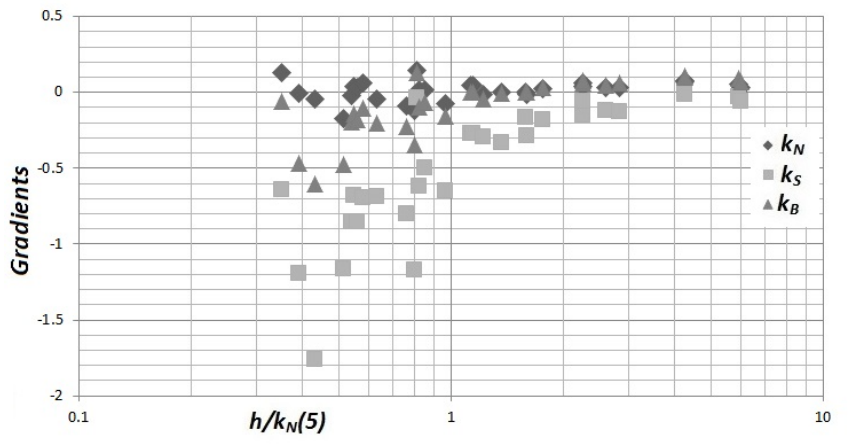

Fig. 11. Relationship of the gradients relative to $k_{N}, k_{S}$ and $k_{B}$ and $h / k_{N}(5)$.

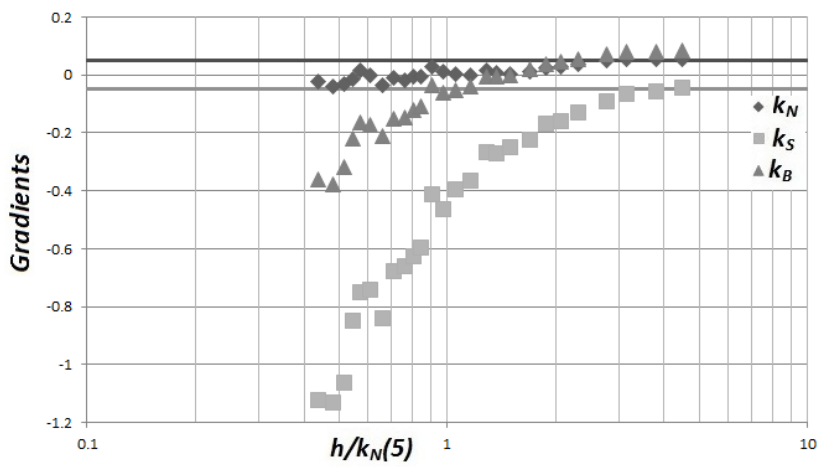

Fig. 12. Moving averages of the gradients relative to of $k_{N}, k_{S}$ and $k_{B}$.

logarithmic regression line, which does not depend on the parameter $D / k$. It is necessary to consider that the Nikuradse equivalent sand-grain roughness $k_{N}$, (as $k_{S}$ and $k_{B}$,) is a sensitive parameter and that its influence on evaluating the flow rate is attenuated by the log in the Keulegan equation.

In the literature, comparisons are generally performed among the measured flow rates $Q_{m}\left(\mathrm{~m}^{3} \mathrm{~s}^{-1}\right)$ and the calculated flow rates $Q_{c}\left(\mathrm{~m}^{3} \mathrm{~s}^{-1}\right)$. The proposed model has been tested using new experimental data from literature and experimental measurements performed for the test (Table 4). The results are shown in Fig. 14. The range of flow rates that is generally

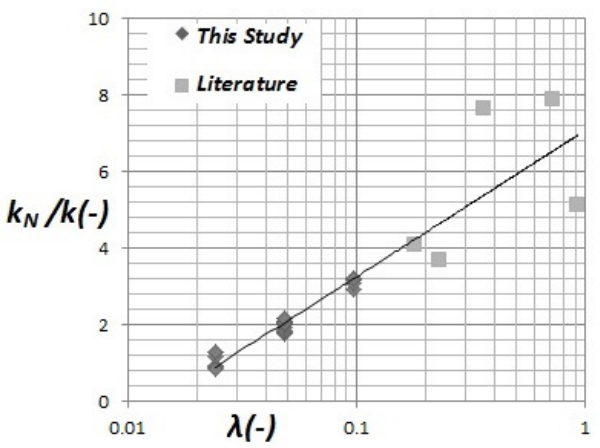

Fig. 13. Ratio of $k_{N} / k$ versus the non-dimensional vegetation density $\lambda$.

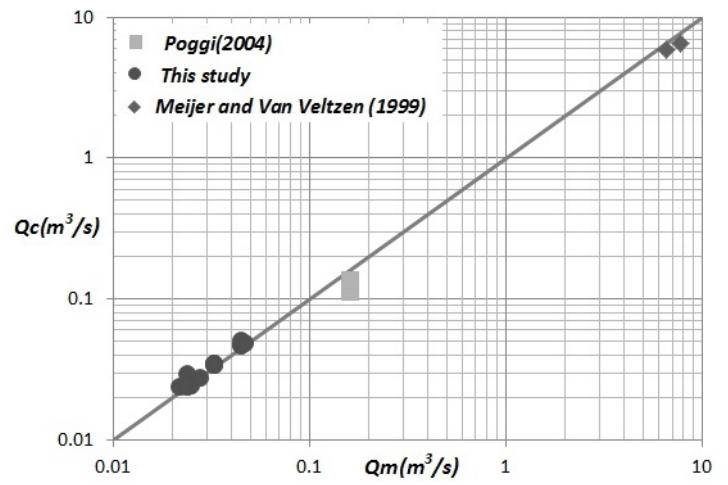

Fig. 14. Comparisons of measured $\left(Q_{m}\right)$ and calculated $\left(Q_{c}\right)$ flow rates.

present in the literature is represented. The flow rates considered in Fig. 14 range across three decades (i.e., $0.01-0.1 \mathrm{~m}^{3} / \mathrm{s}$, $0.1-1 \mathrm{~m}^{3} / \mathrm{s}$ and $\left.1-10 \mathrm{~m}^{3} / \mathrm{s}\right)$. In Cheng $(2011)$, there are four decades (i.e., $0.001-0.01 \mathrm{~m}^{3} / \mathrm{s}, 0.01-0.1 \mathrm{~m}^{3} / \mathrm{s}, 0.1-1 \mathrm{~m}^{3} / \mathrm{s}$ and $1-10 \mathrm{~m}^{3} / \mathrm{s}$ ) and it is clear the lack of literature data in the third decade, which corresponds to the second in Fig. 14.

Measured and experimental data are in good agreement, considering the simplicity of the model, which allows for the evaluation of the Nikuradse equivalent sand-grain roughness $k_{N}$ for high submergences, starting only from the non-dimensional vegetation density.

Table 4. Data to test the model.

\begin{tabular}{|c|c|c|c|c|c|c|c|c|c|c|}
\hline Authors & Arr. & $Q\left(\mathrm{~m}^{-3} \mathrm{~s}^{-1}\right)$ & $V(\mathrm{~m} / \mathrm{s})$ & $h_{u}(\mathrm{~m})$ & $F r$ & $k(\mathrm{~m})$ & $D(\mathrm{~m})$ & $m\left(\mathrm{~m}^{-2}\right)$ & $\lambda$ & $h / k$ \\
\hline \multirow{2}{*}{ Poggi (2004) } & \multirow{2}{*}{ Al. } & 0.162 & 0.300 & 0.6 & 0.124 & 0.12 & 0.004 & 536 & 0.257 & 5.000 \\
\hline & & 0.162 & 0.300 & 0.6 & 0.124 & 0.12 & 0.004 & 1072 & 0.515 & 5.000 \\
\hline \multirow{2}{*}{$\begin{array}{l}\text { Meijer and Van Velzen } \\
(1999)\end{array}$} & \multirow{2}{*}{ Al. } & 5.92 & 0.836 & 2.46 & 0.174 & 0.45 & 0.008 & 256 & 0.922 & 5.467 \\
\hline & & 6.57 & 0.883 & 2.48 & 0.179 & 0.45 & 0.008 & 64 & 0.230 & 5.511 \\
\hline \multirow{16}{*}{ Current work } & \multirow{10}{*}{ Al. } & 0.022 & 0.648 & 0.085 & 0.710 & 0.015 & 0.004 & 1600 & 0.096 & 5.660 \\
\hline & & 0.033 & 0.803 & 0.103 & 0.799 & 0.015 & 0.004 & 1600 & 0.096 & 6.853 \\
\hline & & 0.045 & 0.915 & 0.123 & 0.834 & 0.015 & 0.004 & 1600 & 0.096 & 8.193 \\
\hline & & 0.033 & 0.956 & 0.086 & 1.039 & 0.015 & 0.004 & 1600 & 0.096 & 5.753 \\
\hline & & 0.045 & 1.096 & 0.103 & 1.093 & 0.015 & 0.004 & 1600 & 0.096 & 6.840 \\
\hline & & 0.033 & 1.070 & 0.077 & 1.230 & 0.015 & 0.004 & 1600 & 0.096 & 5.140 \\
\hline & & 0.045 & 1.230 & 0.092 & 1.298 & 0.015 & 0.004 & 1600 & 0.096 & 6.100 \\
\hline & & 0.045 & 1.442 & 0.078 & 1.649 & 0.015 & 0.004 & 400 & 0.024 & 5.200 \\
\hline & & 0.033 & 0.967 & 0.085 & 1.057 & 0.015 & 0.004 & 400 & 0.024 & 5.687 \\
\hline & & 0.024 & 0.583 & 0.103 & 0.580 & 0.015 & 0.004 & 400 & 0.024 & 6.867 \\
\hline & \multirow{6}{*}{ Stag. } & 0.033 & 0.959 & 0.086 & 1.044 & 0.015 & 0.004 & 400 & 0.024 & 5.733 \\
\hline & & 0.045 & 1.082 & 0.104 & 1.071 & 0.015 & 0.004 & 400 & 0.024 & 6.933 \\
\hline & & 0.025 & 0.791 & 0.079 & 0.899 & 0.015 & 0.004 & 800 & 0.048 & 5.267 \\
\hline & & 0.028 & 0.824 & 0.085 & 0.902 & 0.015 & 0.004 & 800 & 0.048 & 5.667 \\
\hline & & 0.024 & 0.769 & 0.078 & 0.879 & 0.015 & 0.004 & 800 & 0.048 & 5.200 \\
\hline & & 0.047 & 1.366 & 0.086 & 1.487 & 0.015 & 0.004 & 800 & 0.048 & 5.733 \\
\hline
\end{tabular}




\section{Link between $h / k_{N}(5)$ and the non-dimensional vegetation density}

Starting from Eq. (39), it is possible to directly link $h / k_{N}(5)$ with the non-dimensional vegetation density using the following equation:

$$
\left[h / k_{N}(5)\right]=\frac{k}{k_{N}}[h / k(5)]=5 \frac{k}{k_{N}}=\frac{5}{2.0116 \ln \lambda+8.1916}
$$

Eq. (40) shows that as the non-dimensional density increases, the value of $h / k_{N}(5)$ decreases and vice versa.

Consequently, the results reported in the literature were confirmed: lower values of $h / k_{N}(5)$ (i.e., less than unity) correspond to higher vegetation densities, and higher values of $h / k_{N}(5)$ (i.e., more than unity) correspond to lower vegetation densities.

\section{Limit and observations of previous results}

A limitation of the previous results is described in this section. The above analysis was performed for values of $h / k_{N}(5)$ that did not exceed 6.02; in Fig. 12, due to the moving average, the maximum value is 4.48 . Clearly, it is not possible to extrapolate these results for the highest values of $h / k_{N}(5)$, or, considering Eq. (18), for densities below 0.024 .

This factor is not a significant limitation. Values of nondimensional vegetation density lower than 0.024 (and consequently values of $h / k_{N}(5)$ higher than approximately 4-6) more typically correspond to rough beds than to vegetated beds (Nepf, 2012).

\section{CONCLUSIONS}

The flow resistance of vegetated flows cannot be described by conventional flow resistance equations such as the Keulegan, Manning or Chézy-Bazin equations. However, within some limitations, particularly in cases with high submergence (i.e., equal to 5 or more), these equations fit experimental data sufficiently well. These results are possible because bulk flow does not distinguish between a rough bed and a vegetated bed in high-submergence scenarios.

An analysis of the experimental data reported in the literature and collected for this study shows that the best equation to evaluate the flow resistance in vegetated flows for submergences of $h / k=5$ or more is the Keulegan equation. For submergences equal or above 5, the Nikuradse equivalent sand-grain roughness $k_{N}$ in the Keulegan equation can be determined using the logarithmic model proposed and tested in this study. These results support the reliability of using conventional flow resistance equations for vegetated flows at high submergence, as already explored in the literature, and, in addition, demonstrate the conventional equations that best fit different flow conditions (i.e., the Keulegan equation) and offer a model to simply evaluate the Nikuradse equivalent sand-grain roughness $k_{N}$ when starting from the non-dimensional vegetation density.

\section{REFERENCES}

Arthington, A.H., Naiman, R.J., McClain, M.E., Nilsson, C., 2010. Preserving the biodiversity and ecological services of rivers: new challenges and research opportunities. Freshwater Biology, 55, 1-16.

Augustijn, D.C.M., Huthoff, F., van Velzen, E.H., 2008. Comparison of vegetation roughness descriptions. In: Proceed- ings of International Conferences on Fluvial Hydraulics (River Flow), Cezme, Izmir, Turkey, pp. 343-350.

Babovic, V., 2000. Data mining and knowledge discovery in sediment transport. Computer-Aided Civil and Infrastructure Engineering, 15, 5, 383-389. DOI: 10.1111/0885-9507.00202.

Babovic, V., Keijzer, M., Aquilera, D.R., Harrington, J., 2001. An evolutionary approach to knowledge induction: Genetic programming in hydraulic engineering. Proceedings of the World Water and Environmental Resources Congress, 111, 64-64.

Babovic, V., 2009. Introducing knowledge into learning based on genetic programming. Journal of Hydroinformatics, 11, 3-4, 181-193.

Baptist, M.J., Babovic, V., Rodriguez Uthurburu, J., Keuzer, M., Uittenbogaard, R.E., Mynett, A., Verwey, A., 2007. On inducing equations for vegetation resistance. J. Hydraul. Res., 45, 4, 435-450.

Bazin, H., 1865. Mémoires présentés par divers savants à l'Académie des Sciences, Paris, France, Vol. 19, 1-494.

Cheng, N.S., 2011. Representative roughness height of submerged vegetation. Water Resour. Res., 47, W08517.

Chow, V.T., 1988. Open Channel Hydraulics. Mc-Graw Hill, New York, NY, USA.

Colebrook, C.F., 1939. Turbulent flow in pipes, with particular reference to the transition between the smooth and rough pipe laws. J. Instn. Civ. Engrs. Eng., 11, 133-156.

De Bos, W.P., Bijkerk, C., 1963. A new monogram for the calculation of water courses. Cultuurtech Tijdschrift, 3, 149155. (In Dutch.)

Dunn, C., Lopez, F., Garcia, M., 1996. Mean flow and turbulence in a laboratory channel with simulated vegetation. Hydrosystems Lab. Hydraulic Eng. Ser. 51, UIUL-ENG-962009, 148 pp., Univ. of Illinois at Urbana-Champaign, Urbana, Illinois, IL, USA.

Galema, A., 2009. Vegetation resistance: evaluation of vegetation resistance descriptors for flood management. MSc Thesis. University of Twente, Enschede, The Netherlands.

Gioia, G., Bombardelli, F.A., 2002. Scaling and similarity in rough channel flows. Phys. Rev. Lett., 88, 1, 14501-14504.

Harris, E.L., Babovic, V., Falconer, R.A., 2003. Velocity predictions in compound channels with vegetated floodplains using genetic programming. International Journal of River Basin Management, 1, 2, 117-123.

Huthoff, F., 2009. Estimating equivalent roughness lengths based on wake sizes. In: Proceedings of 33rd IAHR Congress, Vancouver, Canada (CD-ROM), pp. 1183-1190.

Huthoff, F., 2012. Theory for flow resistance caused by submerged roughness elements. J. Hydraul. Res., 50, 1, 10-17.

Huthoff, F., Augustijn, D.C.M., 2006. Hydraulic resistance of vegetation: predictions of average flow velocities based on a rigid-cylinders analogy. Civil Engineering \& Management Report 2006R-001/WEM-003, University of Twente, Twente, The Netherlands.

Huthoff, F., Augustijn, D.C.M., Hulscher, S.J.M.H., 2007. Analytical solution of the depth-averaged flow velocity in case of submerged rigid cylindrical vegetation. Water Resour. Res., 43, W06413.

Keijzer, M., Babovic, V., 2002. Declarative and preferential bias in GP-based scientific discovery. Genetic Programming and Evolvable Machines, 3, 1, 41-79.

Keulegan, G.H., 1938. Laws of turbulent flow in open channels. Research paper RP1151, J. Res. Nat. Bur. Stand., 121, 6, 707-741.

Klopstra, D., Barneveld, H.J., Van Noortwijk, J.M., Van Velzen, E.H., 1997. Analytical model for hydraulic roughness of 
submerged vegetation. In: Proceedings 27th IAHR Congress,San Francisco, CA, USA, pp. 775-780.

Konings, A.G., Katul, G.G., Thompson, S.E., 2012. A phenomenological model for the flow resistance over submerged vegetation. Water Resour. Res., 48, W02522.

Kouwen, N., 1992. Modern approach to design of grassed channels. J. Irrig. Drain. Eng., 118, 5, 733-743.

Lopez, F., Garcia, M., 1997. Open-channel flow through simulated vegetation: turbulence modeling and sediment transport. Wetlands Research Program Technical Report WRP-CP-10, Dept. of Civil Eng., Univ. of Illinois at Urbana-Champaign, Urbana, Illinois, IL, USA.

Lopez, F., Garcia, M., 2001. Mean flow and turbulence structure of open-channel flow through non-emergent vegetation. J. Hydraul. Eng., 127, 5, 392-402.

Marchi, E., 1961a. Il moto uniforme delle correnti liquide nei condotti chiusi ed aperti. L'Energia Elettrica, 38, 4, 289301. (In Italian.)

Marchi, E., 1961b. Il moto uniforme delle correnti liquide nei condotti chiusi ed aperti. L'Energia Elettrica, 38, 5, 393413. (In Italian.)

Marion, A., Nikora, V., Puijalon, S., Bouma, T., Koll, K., Ballio, F., Tait, S., Zaramella, M., Sukhodolov, A., O'Hare, M., Wharton, G., Aberle, J., Tregnaghi, M., Davies, P., Nepf, H., Parker, G., Statzner, B., 2014. Aquatic interfaces: a hydrodynamic and ecological perspective. J. Hydraul. Res., 52, 6, 744-758.

Meijer, D.G., Van Velzen, E.H., 1999. Prototype-scale flume experiments on hydraulic roughness of submerged vegetation. In: Proceedings of 28th IAHR Congress, Graz, Austria.

Nepf, H.M., 2012. Flow and transport in region with aquatic vegetation. Annu. Rev. Fluid Mech., 44, 123-142.

Nepf, H.M., 2012. Hydrodynamics of vegetated channels. J. Hydraul. Res., 50, 3, 262-279.

Nepf, H., Ghisalberti, M., 2008. Flow and transport in channels with submerged vegetation. ActaGeophysica, 56, 3, 753-777.

Nepf, H.M., Vivoni, E.R., 2000. Turbulence structures in depth-limited, vegetated flow. J. Geophys. Res., 105, C12, 28547-28557.

Nezu, I., Sanjou, M., 2008. Turbulence structure and coherent motion in vegetated canopy open-channel flows. J. HydroEnviron. Res., 2, 62-90.

Poff, L.N., Allan, D.J., Bain, M.B., Karr, J.R., Prestegaard, K.L., Richter, B.D., Sparks, R.E., Stromberg, J.C., 1997. The natural flow regime: a paradigm for river conservation and restoration. BioScience, 47, 11, 769-784.

Poggi, D., Porporato, A., Ridolfi, L., Albertson, J.D., Katul, G.G., 2004. The effect of vegetation density on canopy sublayer turbulence. Boundary-Layer Meteorology, 111, 3, 565-587.

Sturm, T.W., 2001. Open Channel Hydraulics. Mc-Graw Hill, New York, NY, USA.

Sturm, T.W., 2010. Open Channel Hydraulics. 2nd Ed. McGraw Hill, New York, NY, USA.

Stone, B.M., Shen, H.T., 2002. Hydraulic resistance of flow in channels with cylindrical roughness. J. Hydraul. Eng., 128, 5, 500-506.

Stott, T., 2010. Fluvial geomorphology. Progress in Physical Geography, 34, 221-245.

Strickler, A., 1923. Some contributions to the problem of velocity formula and roughness factors for rivers, canals, and closen conduits. Mitteilungen des eidgenössischen Amtes für Wasservirtschaft, Bern, Switzerland, no. 16. (In German.)
Tsujimoto, T., Kitamura, T., 1990. Velocity profile of flow in vegetated-bottom channels. KHL Progressive Report, Hydraulic Laboratory, Kanazawa University, Kanazawa City, Japan.

Tsujimoto, T., Shimizu, Y., Kitamura, T., Okada, T., 1992. Turbulent open-channel flow over bottom covered by rigid vegetation. J. Hydrosci. Hydraul. Eng., 10, 2, 13-25.

Van Velzen, E.H., Jesse, P., Cornelissen, P., Coops, H., 2003. Stromingsweerstand vegetatie in uiterwaarden. Handbook, Part 1 and 2, RIZA Reports 2003.028 and 2003.029, Arnhern, The Netherlands.

Vargas-Luna, A., Crosato, A., Uijttewaal, W.S.J., 2015. Effects of vegetation on flow and sediment transport: comparative analysis and validation of predicting models. Earth Surface and Landforms, 40, 157-176.

Yang, W., Choi, S.U., 2010. A two layer approach for depthlimited open-channel flows with submerged vegetation. J. Hydraul. Res., 48, 4, 466-475.

Yan, J., 2008. Experimental study of flow resistance and turbulence characteristics of open channel flow with vegetation. Ph.D. Thesis. Hohai University, Hohai, China.

Yen, B.C., 1992. Dimensionally homogeneous Manning's formula. J. Hydraul. Eng., 118, 9, 1326-1332.

Yen, B.C., 2002. Open channel flow resistance. J. Hydraul. Eng., 128, 1, 20-39.

\section{NOMENCLATURE}

$B \quad$ Bazin roughness coefficient $\left[\mathrm{m}^{1 / 2}\right]$

$B_{0} \quad$ Correction factor $\left[\mathrm{m}^{1 / 2} \mathrm{~s}^{-1}\right]$

$C$ Chezy resistance factor $\left[\mathrm{m}^{1 / 2} \mathrm{~s}^{-1}\right]$

$C_{D} \quad$ Drag coefficient

$\mathrm{Cu}$ Dimensionless factor

$D \quad$ Vegetation diameter [m]

$f$ Darcy-Weisbach friction factor

$\mathrm{Fr} \quad$ Froude number

$g$ Acceleration of gravity $\left[\mathrm{m} / \mathrm{s}^{2}\right]$

$h$ Flow depth [m]

$h_{u} \quad$ Uniform flow depth [m]

$k \quad$ Vegetation height [m]

$k_{B} \quad$ Chezy-Bazin roughness height [m]

$k_{N} \quad$ Nikuradse equivalent sand-grain roughness [m]

$k_{S} \quad$ Strickler roughness height [m]

$K n$ Conversion factor $\left[\mathrm{m}^{1 / 2} \mathrm{~s}^{-1}\right]$

$K_{\rho} \quad$ Dimensionless factor

$K_{\Phi} \quad$ Correction factor $\left[\mathrm{m}^{1 / 2} \mathrm{~s}^{-1}\right]$

$K_{1} \quad$ Dimensionless factor

$K_{2}$ Dimensionless factor

$h / k \quad$ Submergence ratio

$m \quad$ Vegetation elements per unit area $\left[\mathrm{m}^{-2}\right]$

$n \quad$ Manning roughness coefficient $\left[\mathrm{m}^{1 / 6}\right]$

$Q \quad$ Flow rate $\left[\mathrm{m}^{3} \mathrm{~s}^{-1}\right]$

$Q_{c} \quad$ Calculated flow rate $\left[\mathrm{m}^{3} \mathrm{~s}^{-1}\right]$

$Q_{m} \quad$ Measured flow rate $\left[\mathrm{m}^{3} \mathrm{~s}^{-1}\right]$

$R \quad$ Hydraulic radius [m]

$s \quad$ Vegetation elements spacing [m]

$S \quad$ Channel slope

$S_{H} \quad$ Total head slope

$\lambda \quad$ Non dimensional vegetation density

$\lambda_{C} \quad$ Fraction of the bed area occupied by vegetation elements

$\Phi_{B} \quad$ Correction factor $\left[\mathrm{m}^{1 / 2} \mathrm{~s}\right]$

$\Phi_{S} \quad$ Correction factor $\left[\mathrm{m}^{-1 / 2} \mathrm{~s}\right]$ 